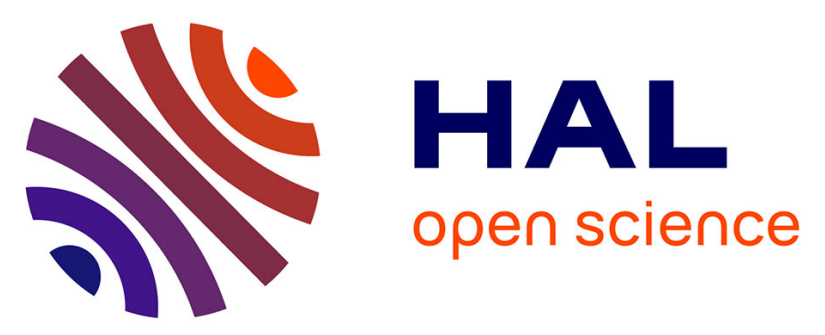

\title{
Le pouvoir modérateur dans la Constitution brésilienne de 1824 et la Charte constitutionnelle portugaise de 1826 : les influences de Benjamin Constant ou de Lanjuinais?
}

Oscar Ferreira

\section{To cite this version:}

Oscar Ferreira. Le pouvoir modérateur dans la Constitution brésilienne de 1824 et la Charte constitutionnelle portugaise de 1826: les influences de Benjamin Constant ou de Lanjuinais?. Revue française de droit constitutionnel, 2012, 89, pp. 1-40. hal-01552771

\section{HAL Id: hal-01552771 \\ https://hal.science/hal-01552771}

Submitted on 30 Apr 2020

HAL is a multi-disciplinary open access archive for the deposit and dissemination of scientific research documents, whether they are published or not. The documents may come from teaching and research institutions in France or abroad, or from public or private research centers.
L'archive ouverte pluridisciplinaire $\mathbf{H A L}$, est destinée au dépôt et à la diffusion de documents scientifiques de niveau recherche, publiés ou non, émanant des établissements d'enseignement et de recherche français ou étrangers, des laboratoires publics ou privés. 


\title{
Le pouvoir modérateur dans la Constitution brésilienne de 1824 et la Charte constitutionnelle portugaise de 1826 : les influences de Benjamin Constant ou de Lanjuinais ?
}

\author{
Par Oscar Ferreira
}

«Le pouvoir modérateur de la Charte [portugaise de 1826] est une invention des publicistes modernes, ce que Benjamin Constant nomme le pouvoir royal ou pouvoir neutre, qui modifie l'action des autres pouvoirs, sans jamais en exercer les fonctions qui leur appartiennent en propre (telle est la différence entre monarchie absolue et monarchie constitutionnelle); par conséquent, en guise d'exemple, le pouvoir modérateur ajourne les chambres mais ne peut légiférer - il renvoie les ministres, mais n'exerce pas le pouvoir exécutif par lui-même - il modère les décisions de justice, mais ne peut juger. Ce pouvoir est défini à l'article 74 de la Charte $»^{1}$. Parmi tant d'autres, le député Aguiar $^{2}$ accréditait la thèse de l'influence au moins théorique de l'illustre libéral français quant à la définition, au rôle et aux attributions du chef de l'Etat portugais tels qu'ils résultaient de l'article 74 de la Charte constitutionnelle de $1826^{3}$. Cette opinion, véritable lieu commun des manuels de droit constitutionnel portugais ${ }^{4}$ et des commentateurs de Constant ${ }^{5}$, était assurément soutenue par les parlementaires lusitaniens sous le règne mouvementé de cette constitution; encore en 1874, le député Carlos Bento retranscrivait l'histoire officielle d'un texte calqué sur la constitution brésilienne de 1824 et octroyé par Dom Pedro $\mathrm{IV}^{6}$ avant qu'il ne renonce au trône du Portugal afin

\footnotetext{
1 Intervention du député Aguiar, 2 novembre 1844, in Diario da Câmara dos Senhores Deputados da Nação Portugueza, legislatura 5, sessão 3, n ${ }^{\circ}$ 0, p. 11. Nous traduirons nous-mêmes tous les passages en portugais. Les version originales seront reléguées en note uniquement en cas de difficulté de traduction.

${ }^{2}$ Le libéral Joaquim Antonio de Aguiar (1792-1874), député dès 1826, fut plusieurs fois ministre de la Justice (1833$1834 ; 1836 ; 1841-1842 ; 1846)$ et fut en particulier à l'origine de l'extinction des ordres religieux au Portugal. Membre du Partido Regenerador, il fut à trois reprises Président du Conseil (1841-1842 ; 1860 ; 1865-1868).

${ }^{3}$ Sur cette Charte, on se référera notamment aux ouvrages suivants: J. Ferreira Borges, Cartilha do Cidadão Constitucional dedicada à Mocidade Portuguesa, Londres, Hansard, 1832 ; S. Pinheiro Ferreira, Observações sobre a Constituição do Imperio do Brasil, e sobre a Carta Constitucional do Reino de Portugal, Paris, Rey et Gravier, 1835 , $2^{\text {ème }}$ édition (1 ${ }^{\text {ère }}$ éd. : 1831) ; J. J. Lopes Praça, Estudos sobre a Carta Constitucional de 1826 e o Acto Adicional de 1852, Coimbra, Imprensa Litteraria, 1878-1880, 3 vol. ; J. Campinos, A Carta Constitucinal de 1826, Lisbonne, Decibel, 1975 ; P. Ferreira da Cunha, Para uma historia constitucional do direito português, Coimbra, Almedina, 1995, p. 381 et s. ; M. Soares, Carta Constitucional, in Dicionario de Historia de Portugal, I, p. 494 et s. ; M. Caetano, Carta Constitucional, in Verbo, IV, p. 1191 et s. De façon générale, appréhendant notamment les acteurs politiques de la période, consulter également: A. J. Ferreira Marnoco e Sousa, Direito politico: Poderes do Estado : sua organização segundo a sciencia politica e o direito constitucional português, Coimbra, França Amado, 1910 ; M. Pinto dos Santos, Monarquia Constitucional. Organização e Relações do Poder Governamental com a Câmara dos Deputados, 1834-1910, Lisbonne, Assembleia da Republica, 1986; M. F. Cruz Canaveira, Liberais Moderados e Constitucionalismo Moderado (1824-1852), Lisbonne, I.N.I.C., 1988, p. 115 et s ; M. de Melo Rocha, A separação dos poderes nas constituições portuguesas do demo-liberalismo de 1820 a 1926, Coimbra, Universidade de Coimbra, 1989 ; Z. M. Osorio de Castro, Dicionario do Vintismo e do primeiro Cartismo (1821-1822 e 1826-1828), Lisbonne, Assembleia da Republica, Afrontamento, 2002, 2 volumes.

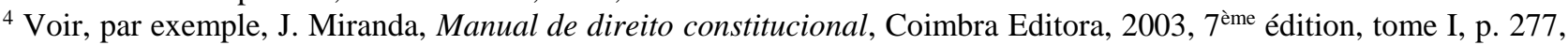
ou encore M. Caetano, Historia breve das constituições portuguesas, Verbo, 1965, p. 29.

${ }^{5}$ Consulter S. Mota Barbosa, «L'influence politique de l'œuvre de Benjamin Constant sur la pratique politique brésilienne », in Annales Benjamin Constant, n²3, pp. 217-234; Th. Diniz Guedes, « Le pouvoir neutre et le pouvoir modérateur dans la constitution brésilienne de 1824 », Ibid., pp. 235-246; Cl. Francisco Alves, « A influência do pensamento liberal de Benjamin Constant na formação do Estado Imperial Brasileiro », in Revista de informação legislativa v. $45, \mathrm{n}^{\circ} 180$, oct./déc. 2008 , notamment pp. 70-73.

${ }^{6}$ Nous conserverons les noms en leur version originale. En France, les ultras faisaient de même. En revanche, les libéraux et les doctrinaires devaient franciser certains noms plus que de raison, l'exemple le plus curieux concernant précisément D. Pedro. Littéralement, «Pedro» correspond au «Pierre» français. Il se trouve que cette traduction n'a pas été retenue au XIX ${ }^{\mathrm{e}}$ siècle, afin de ne pas entretenir de confusions avec le tsar de Russie : en effet, Pedro IV du Portugal n'est autre que Pedro I du Brésil. De Mme de Staël à François Guizot, les libéraux au sens large ont préféré consacrer la dénomination, quelque peu barbare, de «Dom Pèdre ».
} 
de se maintenir au Brésil : "Notre charte est copiée de celle du Brésil, elle qui contient les principes les plus conformes au libéralisme, à l'instar, par exemple, du pouvoir modérateur, plus divers que ce que l'on pensait, principe qui est la traduction des idées constitutionnelles de Benjamin Constant $[\ldots]]^{7}$. Le monde «portugais » se glorifie depuis d'avoir été le seul à consacrer l'idée du pouvoir modérateur en droit positif, au rebours de la France où le concept fut pourtant souvent débattu.

Comme toute « légende » constitutionnelle, celle-ci contient sans doute une part de vérité ${ }^{8}$; elle n'en intrigue pas moins les commentateurs les plus avisés : contrairement aux leçons du libéral de Coppet, le pouvoir modérateur des constitutions des pays lusophones n'implique pas l'exclusion du Roi du domaine du pouvoir exécutif. Au contraire, les deux textes visés se plaisent à confier au chef de l'Etat deux attributions distinctes : le Roi et l'Empereur incarnent en effet à la fois le rôle de chef de l'Exécutif (article 75 de la Charte portugaise de 1826; article 102 de la Constitution brésilienne de 1824) et celui de pouvoir modérateur (respectivement aux articles 71 et 98).

Faut-il en déduire que les Portugais et les Brésiliens se sont égarés dans leur interprétation du pouvoir neutre? Une telle conviction est aujourd'hui courante chez les professeurs brésiliens : en soulignant le fait que l'Empereur du Brésil est un «pouvoir politiquement militant», Paulo Bonavides parle ainsi de «déformation des idées de Constant ${ }^{9}$. Ce même auteur en révèle les raisons politiques: si l'empereur, malgré d'évidentes ambiguïtés liées à son tempérament, paraissait séduit par les idées libérales, les rédacteurs de la constitution octroyée étaient sans doute mus par le désir d'asseoir insidieusement une monarchie absolue ${ }^{10}$ ou du moins d'empêcher l'instauration d'une monarchie parlementaire à l'anglaise. Le professeur Afonso Arinos de Melo Franco déplorait la réussite de cette entreprise, en imputant au pouvoir modérateur l'absence du véritable parlementarisme sous le Brésil impérial ${ }^{11}$. Le pouvoir modérateur ne serait alors qu'une façade douteuse travestissant un libéralisme français, brillant mais inapplicable, réduit au statut de caution de probité ; ainsi se perpétue la célèbre et virulente critique du Times portée à l'encontre de la Constitution brésilienne de 1824.

Avancer de telles considérations à propos du Portugal semble en revanche plus hasardeux. Tiraillé entre les libéraux, héritiers du mouvement vintista et soutiens de la reine D. Maria II, fille de D. Pedro, et les partisans de la monarchie absolue, partisans de D. Miguel, frère de D. Pedro, le pays souffre d'une opposition radicale susceptible de le diviser et ainsi de justifier l'apparition d'un quatrième pouvoir chargé d'arbitrer les différents partis ; pouvoir qu'il convenait de concilier avec un parlementarisme désiré, suivant le modèle expérimenté par le «tuteur» anglais. D. Miguel laissait pourtant bien entendre qu'il refusait de se limiter à un pouvoir modérateur qui, de ce côté de l'Atlantique, se comprenait comme un prélude à l'effacement du monarque, dilué dans un régime

\footnotetext{
${ }^{7}$ Carlos Bento, intervention du 20 mars 1874, in Diario da Câmara dos Senhores Deputados da Nação Portugueza, legislatura 20, sessão $4, n^{\circ} 52$, p. 821.

${ }^{8}$ A l'exception des références à Auguste Comte, qui s'avèrent ici anachroniques comme le relève J-J. Faust, Le Brésil : chroniques d'une démocratisation, Paris, L'Harmattan, 1998, p. 76.

${ }^{9}$ P. Bonavides, «O poder moderador na constituição do império », in Revista de informação legislativa, v. $11, \mathrm{n}^{\circ} 41$, mars 1974, pp. 29-30.

${ }^{10}$ Ibid., p. 29 : «Mais ces auteurs de la Constitution, peut-être mus par des penchants absolutistes inconscients et enracinés, que l'attitude contradictoire et impulsive de l'Empereur semblait refléter, ne sont pas parvenus à assimiler la leçon libérale de Constant [...] ». L'auteur n'échappe pas ici au procès d'intention qui se propagea tout le long du XIX ${ }^{\mathrm{e}}$ siècle.

11 «Le prétendu parlementarisme impérial brésilien n'a jamais existé, du moins le véritable système de gouvernement parlementaire, élaboré en Europe par la pratique anglaise, et fixé sur le continent par le constitutionnalisme du XIX siècle. Au Brésil, l'institution du Pouvoir Modérateur au sein de la constitution - exemple unique au monde - fit de notre prétendu gouvernement parlementaire quelque chose de sui generis, totalement différent de ce que la doctrine a conceptualisé sous ce nom ». A. Arinos de Melo Franco, Estudos de Direito Constitucional, Rio de Janeiro, 1957, p. 29. Cette référence à un gouvernement sui generis n'est pas sans évoquer le célèbre discours de Thiers qui employait la même expression afin de définir la jeune monarchie de Juillet. Voir son discours sur la garantie de l'emprunt grec, 8 juin 1833, in Discours parlementaires de M. Thiers, Paris, Calmann Lévy, 1879, tome II, p. 158.
} 
parlementaire remis aux mains des partis; sa pratique du pouvoir, entre 1828 et 1834, n'offre aucune ambiguïté sur ce sujet ${ }^{12}$. En dépit des origines communes des textes constitutionnels, la «machination subreptice » reprochée à l'Empereur du Brésil ne peut donc suffire à exposer la réalité portugaise.

Cet élément de réponse est d'autant plus fragile qu'il occulte allègrement une autre donnée d'importance susceptible d'expliquer ces mésententes constitutionnelles. Dans des pays où l'influence des publicistes français est considérable, quoique parfois ambigue ${ }^{13}$, il semble en effet plausible que les rédacteurs de ces constitutions lusophones aient été influencés par la myriade de théories concurrentes à celle de Constant. L'omniprésence du concept de pouvoir modérateur dans les milieux intellectuels de la Restauration, abordé sous différentes dénominations de prime abord convergeantes (pouvoirs neutre, conservateur, modérateur, préservateur, régulateur...), doit alerter notre attention; loin d'être interchangeables, ces appellations entretiennent en effet une polysémie redoutable d'autant plus pernicieuse qu'elle concerne les membres d'un même camp politique.

La théorie de Benjamin Constant ${ }^{14}$ constituait à l'origine une réponse aux errements de la Révolution et aux carences des constitutions modernes ${ }^{15}$. Constatant les insuffisances de la mise en œuvre de la séparation des pouvoirs, il souhaitait instituer un mécanisme régulateur, strictement cantonné dans la sphère constitutionnelle ${ }^{16}$ et ainsi exclu de la lutte politique ; il voulait ainsi donner naissance à un quatrième pouvoir doté d'une nature ou, pour reprendre le vocabulaire de la revue libérale La Minerve française, auquel il collabora, une métaphysique qui lui serait propre ${ }^{17}$. S'il va progressivement s'en démarquer, Constant renouait ainsi avec l'idée du "pouvoir régulateur », expression consacrée sous la Révolution qui désigne un pouvoir, remis soit à une assemblée spécifique, soit à la chambre haute ${ }^{18}$, chargé de rétablir l'équilibre en usant de son ascendant naturel, autrement dit de façon discrétionnaire. Ce concept était déjà associé à celui de «pouvoir modérateur », également discrétionnaire, dont la fonction consiste originairement à garantir les droits en résistant à tout abus d'autorité et à toute usurpation du pouvoir constituant. En

\footnotetext{
${ }^{12}$ Voir de préférence l'article de V. Pulido Valente, «Os Levantamentos Miguelistas contra a Carta Constitucional (1826-1827) », in Analise Social, n¹33, Lisbonne, 1995, pp. 631-651. Sur la contre-révolution portugaise, on pourra se reporter aux ouvrages de M. Alexandre Lousada, O miguelismo (1828-1834) : o discurso politico e o apoio da nobreza titulada, Lisbonne, 1987 et El miguelismo o la contrarevolucion en Portugal, Madrid, s. e., 1996.

${ }^{13}$ Cf. Fr. Chevalier/J. Chazelas, «Le Brésil différent : un héritage original de la Révolution française », in Cahiers des Amériques latines, Paris, IHEAL éditions, 1990, $\mathrm{n}^{\circ} 10$, pp. 205-223. L’article expose un historique du règne de la constitution de 1824, abordant au passage la question du pouvoir modérateur.

${ }^{14}$ Sur le pouvoir neutre, voir de préférence P. Rolland, « Comment préserver les institutions ? La théorie du pouvoir neutre de Benjamin Constant », in Revue Française d'Histoire des Idées Politiques, n²7, 2008, pp. 43-74 et, en complément, E. Travers, Benjamin Constant. Les principes et l'histoire, Paris, H. Champion, 2005, pp. 540-551. D'une façon générale, sur le thème du quatrième pouvoir entre 1814 et 1848, nous renvoyons à notre thèse : Le pouvoir royal (1814-1848). A la recherche du quatrième pouvoir?, thèse, Droit, Université Paris-Est, 2010.

${ }^{15}$ En dépit de la publication en 1991 de ses Fragments d'un ouvrage abandonné sur la possibilité d'une constitution républicaine dans un grand pays, où apparaît l'idée de son pouvoir préservateur, les contemporains restreignent encore trop souvent leurs lectures de Constant aux Principes de politique de 1815. Il en résulte un contresens fâcheux, aisé à repérer dans l'ouvrage d'A. Enders, Histoire du Brésil contemporain XIX ${ }^{e}-X X^{e}$ siècles, Paris, éditions complexe, 1997, p. 27 : le pouvoir modérateur devient ainsi une création offerte à Bonaparte sous les Cent-Jours, prêtant ainsi le flanc aux critiques qui n'y voient qu'un paravent du despotisme. Cette accusation fut il est vrai courante au Brésil.

16 «Le pouvoir exécutif, le pouvoir législatif, et le pouvoir judiciaire, sont trois ressorts qui doivent coopérer, chacun dans sa partie, au mouvement général : mais quand ces ressorts dérangés se croisent, s'entrechoquent et s'entravent, il faut une force qui les remette à leur place. Cette force ne peut pas être dans l'un des ressorts, car elle lui servirait à détruire les autres. Il faut qu'elle soit en dehors, qu'elle soit neutre, en quelque sorte, pour que son action s'applique nécessairement partout où il est nécessaire qu'elle soit appliquée, et pour qu'elle soit préservatrice, réparatrice, sans être hostile ». Principes de politique (version 1815), in Ecrits politiques, éd. M. Gauchet, Paris, Gallimard, 1997, p. 324.

${ }^{17}$ Voir l'article d'E. Aignan, paru dans la Minerve française, tome III, août 1818, p. 340, où il reconnaissait les vertus de cette «abstraction métaphysique », mettant ainsi au jour l'essence particulière du pouvoir royal, par opposition aux autres théories libérales qui n'en font qu'un rouage de leurs théories sur l'exercice du Pouvoir.

18 Voir M. Gauchet, La Révolution des pouvoirs. La souveraineté, le peuple et la représentation 1789-1799, Paris, Gallimard, 1995, pp. 96-97.
} 
présentant pour la première fois son idée en 1814 dans ses Réflexions sur les constitutions, Constant cultivait néanmoins son originalité en offrant le pouvoir régulateur ou préservateur au chef de l'Etat; il se démarquait ainsi de la quasi totalité de ses prédécesseurs qui, à l'exception importante de Bernardin de Saint-Pierre, n'ont jamais envisagé le Roi tel un pouvoir modérateur. De façon plus marquante, Constant rompait également avec lui-même, lui dont le projet initial visait à confier ce même pouvoir à une assemblée politique particulière. Pour se justifier, il devait invoquer la méthode historique régulièrement bafouée par les acteurs de la Révolution qui préférèrent opter pour la politique de la table rase ; aussi, loin de suivre les brisées anglaises, et afin de prévenir les attaques prétextant d'une mauvaise acclimatation d'idées en provenance de l'étranger, Constant fit régulièrement l'effort de démontrer que son idée provient de France : ce n'est pas au king can do no wrong mais à l'adage «Ah, si le roi savait... » qu'il en attribuait les origines ${ }^{19}$.

En dehors de Charles Dunoyer dans les pages du Censeur en 1815, rares sont les libéraux à avoir véritablement suivi ou même compris sa leçon ; le contexte de la Restauration les obligeait néanmoins à reconsidérer la place du roi dans les institutions remodelées par la Révolution. Suivant la voie initiée par Lanjuinais en 1819 dans son essai politique adjoint à ses Constitutions de la nation française, un nombre conséquent des libéraux prônait une vision faussement proche de celle du libéral de Coppet. La principale différence avec la théorie de Constant devait provenir de la double mission qui incombe au chef de l'Etat, écartant ainsi son concept très particulier de neutralité. Pour Pellegrino Rossi, il ne faisait aucun doute que le Roi devait être à la fois un «principe moteur et conservateur ${ }^{20}$. Le chef de l'Etat apparaissait tantôt comme un arbitre, tantôt tel un capitaine, s'adaptant de la sorte à toutes les situations : à ce titre, il devait être investi du pouvoir exécutif ou du moins en être le chef. En présentant l'idée comme un legs de la théorie des deux corps du Roi, le libéral Hello en minimisait sans doute l'originalité pour mieux la faire accepter $^{21}$; la reprise n'en demeurait pas moins astucieuse en dissociant dans le même homme l'institution, neutre et habilitée à ce titre à accomplir une mission d'arbitrage (principe conservateur), du prince, pouvoir actif ancré dans le gouvernement (principe moteur). Cette approche du sujet s'acceptait d'autant plus aisément qu'elle renouait d'une autre manière la chaîne des temps en développant un concept déjà défendu par Bernardin de Saint-Pierre dans ses Voux d'un solitaire, paru en septembre 1789. Pour ce disciple de Rousseau, il importait effectivement d'introduire un "pouvoir modérateur » entre les pouvoirs exécutif (nommé «pouvoir exécuteur ») et législatif (rebaptisé «pouvoir législateur ») ${ }^{22}$. Mais, à la différence de ses contemporains de la Révolution, la mission incombait selon lui au roi, qui assumait ainsi deux fonctions : celle de pouvoir exécuteur (ou pouvoir exécutif) et celle de pouvoir modérateur (ou pouvoir «modératif »).

\footnotetext{
19 «Dans ces contrées plus civilisées et moins malheureuses, l'expression consacrée comme le cri du faible et de l'opprimé, si le roi savait! n'est autre chose encore qu'un hommage rendu à la même vérité. C'est le sentiment précédant la doctrine ; mais comme la doctrine n'avait jamais été énoncée, ce sentiment, cet instinct confus ont été la cause d'erreurs très dangereuses. De ce qu'on sentait vaguement que le pouvoir royal était par sa nature une autorité neutre qui, renfermée dans ses limites, n'avait pas de prérogatives nuisibles, on en a conclu qu'il n'y aurait pas d'inconvénients à l'investir de ces prérogatives, et la neutralité a cessé ». B. Constant, article de La Minerve française, tome V, février 1819 , pp. 80-81.

${ }^{20}$ Voir P. Rossi, Cours de droit constitutionnel, Paris, Guillaumin et Cie, 1877, 2 ème édition, tome IV, pp. 219-220.

${ }^{21}$ Voir en particulier Ch.-G. Hello, Essais sur le régime constitutionnel ou introduction à l'étude de la Charte, Paris, Le Normant, 1827, notamment p. 101 et s. Sans l'avoir semble-t-il lu, M. Gauchet avait pressenti que les libéraux s'étaient inspirés de cette fiction issue du droit public d'Ancien régime. Voir son article « Des deux corps du roi au pouvoir sans corps. Christianisme et politique », in Le Débat, n ${ }^{\circ} 4,1981$, p. 136.

22 «Plusieurs écrivains célèbres considèrent le pouvoir national dans la monarchie, comme divisé en deux ; en pouvoir législateur, et en pouvoir exécuteur : ils en attribuent le premier à la nation, et le second au roi. Cette division me paraît insuffisante, parce qu'il y manque un troisième pouvoir, nécessaire à tout bon gouvernement, le pouvoir modérateur, qui appartient essentiellement au roi dans la monarchie ». Vœux d'un solitaire (septembre 1789), in CEuvres complètes de Jacques-Henri Bernardin de Saint-Pierre, Paris, Méquignon-Marvis, 1828, tome XI, p. 64.
} 
La thèse de Lanjuinais nous a déjà paru l'emporter en France dans les milieux libéraux favorables à l'idée du pouvoir modérateur conféré au Roi ${ }^{23}$; ceci nous oblige à étudier les sources manifestement françaises de l'idée lors du processus constituant brésilien, avant d'en mesurer la progression dans les débats animant la vie politique du pays (I). Il faudra ensuite s'enquérir de son application au Portugal, afin d'essayer d'en déterminer la paternité, en se demandant si, finalement, ce ne sont pas les pensées de Constant et de Lanjuinais qui ont été mal interprétées, en raison d'une confusion, déjà persistante au Brésil, entre pouvoir régulateur et pouvoir conservateur (II).

\section{I- Les sources du pouvoir modérateur: l'amalgame des idées françaises par la politique brésilienne}

«En effet, nous sommes convaincus, jusqu'à preuve du contraire, que la théorie du Pouvoir royal ou Pouvoir Modérateur, adoptée à la suite des publicistes français par la constitution brésilienne, répond de façon satisfaisante, comme nous le démontrerons, à la difficulté soulevée [à propos des insuffisances de la séparation des pouvoirs] ${ }^{24}$. Publiée en 1864 , la première étude sérieuse sur le pouvoir modérateur du Brésil par le professeur de droit Braz Florentino Henriques de Souza confessait les multiples emprunts de l'idée du pouvoir modérateur non au seul Benjamin Constant, mais à la multitude des publicistes français ayant, sous la Restauration puis sous la monarchie de Juillet, travaillé sur ce sujet. Un bref parcours de l'ouvrage atteste de l'exubérance de ces sources, que le professeur de l'Université de Recife puise dans Constant, Lanjuinais, Lorieux, Rossi, Destutt de Tracy, Henri Fonfrède et parfois... Bonald. Le tout sans évoquer les fréquents emprunts aux théoriciens de la Révolution française ayant plus ou moins esquissé l'idée d'une séparation entre pouvoir royal et pouvoir ministériel : Malouet, Clermont-Tonnerre ou encore Lally Tollendal sont ainsi cités. La pensée constitutionnelle française s'impose ainsi continuellement ${ }^{25}$, au point d'éclipser les auteurs anglais, dont le parlementarisme « anarchisant » est souvent critiqué ${ }^{26}$, ou de voir les publicistes allemands comme Robert von Mohl, Frédéric Ancillon ou encore d'Arretin, cités uniquement à travers leurs traductions françaises, qu'il s'agisse de celles assurées par Guizot ou par Charles Auguste Pellat.

Une telle profusion ne doit pourtant pas surprendre, tant elle est commune aux classes éclairées brésiliennes ${ }^{27}$, en particulier dans les milieux conservateurs partisans de l'Empereur. Sur ce point, celui-ci leur ressemblait : comme en atteste dès 1827 Eugène de Monglave, traducteur et éditeur de la correspondance entre Dom Pedro et son père Dom João VI, si l'empereur du Brésil «connaît à fond toutes les œuvres de Benjamin Constant», il a aussi et surtout "médité les publicistes français dont les écrits passent fréquemment de la bibliothèque publique dans son cabinet particulier $»^{28}$. Cette abondance certifiée des sources françaises ${ }^{29}$, à laquelle ne sont pas

\footnotetext{
${ }^{23}$ Voir O. Ferreira, Le pouvoir royal (1814-1848) : A la recherche du quatrième pouvoir ?, op. cit., pp. 589-637.

${ }^{24} \mathrm{Br}$. Fl. Henriques de Souza, Do poder moderador. Ensaio de direito constitucional contendo a analyse do Titulo $V$, Capitulo I, da Constituição politica do Brazil, Recife, Typographia universal, 1864, pp. 9-10.

${ }^{25}$ Elle touche d'ailleurs toute la pensée juridique, comme en attestent les fréquents emprunts à des jurisconsultes comme Portalis, Toullier ou encore Demolombe.

${ }^{26}$ Voir en particulier Ibid., p. 209. Le parlementarisme anglais ne serait selon lui que le cheval de Troie de l'oligarchie.

${ }^{27} \mathrm{Au}$ Brésil, les « fils de famille » étaient habituellement envoyés en Europe pour suivre des études de droit ; trois destinations étaient prisées : Coimbra, de façon logique, mais aussi Paris et plus encore Montpellier, expliquant ainsi l'influence française. Voir Ch. Morazé, Les trois âges du Brésil. Essai de politique, Paris, Armand Colin, 1954, p. 25.

${ }^{28}$ Correspondance de Don Pèdre premier, empereur constitutionnel du Brésil, avec le feu Roi de Portugal, Don Jean VI, son père, durant les troubles du Brésil, par Eugène de Monglave, Paris, Tenon, 1827, p. 88. D. Pedro ne se limitait pas aux publicistes habituellement lus ; Monglave précise ainsi que celui-ci a « dévoré » les discours du général Foy.

${ }^{29}$ Elles constituent ainsi les principales sources intellectuelles du Brésil dans son accession à l'indépendance. Voir C. Guilherme Mota, «Le Brésil : aspects d'ensemble de la période (1750-1831)», in Les révolutions dans le monde ibérique, tome II : l'Amérique, Presses universitaires de Bordeaux, 1991, pp. 335-362 et surtout N. Nogueira Saldanha, Historia das Idéias Politicas no Brasil, Brasilia, Senado Federal, Coleção Biblioteca Basica Brasileira, 2001, p. 90. Selon lui, les publicistes français sont notamment connus via le travail de «prosélytisme rationnaliste » (sic) des francsmaçons. Il atteste de toute façon que les livres sont directement lus en français et parfois traduits tout au long de la première partie du XIX ${ }^{\mathrm{e}}$ siècle (Ibid., p. 120).
} 
étrangers des journaux qui, comme $O$ Farol Paulistano, n'hésitent pas à traduire Constant, Lanjuinais, Royer-Collard et Daunou ${ }^{30}$, suscite néanmoins l'interrogation: la pensée constitutionnelle brésilienne se serait-elle fourvoyée en assimilant, à tort, une multitude d'auteurs français aux convictions et aux thèses en vérité fort différentes? En effet, en dépit d'un vocabulaire parfois trompeur, les publicistes français ne défendaient pas la même idée. Si Constant et Lanjuinais faisaient du pouvoir royal l'héritier des «pouvoirs régulateurs » exposés sous la Révolution, ces mécanismes purement constitutionnels chargés de veiller sur l'équilibre des pouvoirs, ils avaient en face d'eux des personnalités influentes comme Fonfrède ou Bonald, tenants d'un " pouvoir conservateur» aux objectifs complexes et politisés : un pouvoir arbitrant les forces sociales du pays en tranchant en faveur de telle opinion ou de tel intérêt, chargé à ce titre de préserver la paix sociale et l'unité du pays, et autorisé à se transformer en pouvoir d'exception si le salut de l'Etat ou de la communauté politique l'exigeait. Faisant fi du droit positif, tout en se réclamant du droit naturel, le roi pouvait s'arroger les pleins pouvoirs en de telles circonstances.

Cette ambivalence n'est pas l'œuvre des Brésiliens. L'expression « pouvoir modérateur» s'avère déjà polysémique dans l'esprit de Bernardin de Saint-Pierre : elle ne couvre pas uniquement la fonction de régulateur entre le Législatif et l'Exécutif, et désigne également un pouvoir que nous nommerons conservateur. En effet, le roi avait également pour but de garantir l'égalité des forces sociales en présence, noblesse et clergé d'un côté, peuple de l'autre :

«Les trois corps de la monarchie [noblesse, clergé, peuple] réagissent sans cesse les uns contre les autres, en sorte que, livrés à eux-mêmes, il arriverait bientôt qu'un d'entre eux opprimerait les deux autres, ou en serait opprimé, sans que le roi, qui n'aurait que le pouvoir exécuteur, pût faire autre chose que d'être l'agent du parti le plus fort, c'est-à-dire de l'oppression. Il faut donc que le roi ait encore le pouvoir modérateur, c'està-dire, celui $[\ldots]$ de maintenir l'équilibre entre ces corps $[\ldots] »^{31}$.

La notoriété bien établie de l'auteur, mort en 1814, permet de croire à une possible influence sur la pensée des libéraux français, d'autant plus que certains d'entre eux, tel le député Kératry, l'un des 221 , furent proches de ce précurseur du romantisme ; la profusion des sources françaises au Brésil peut également nous inciter à croire qu'il y eût du crédit, ses œuvres ayant bénéficié d'une traduction en portugais suite au succès de Paul et Virginie. En tout état de cause, l'amphibologie de l'expression " pouvoir modérateur » sous la plume de Bernardin de Saint-Pierre interpelle ; car le roi, à la différence du Tribunat de Rousseau (Contrat social, livre IV, ch. V), fait toujours partie de la cité : il ne lui est pas extérieur et a noué par conséquent des liens avec ses diverses composantes, jetant au moins le doute quant à sa possible neutralité dans les conflits. Dans ces conditions, le roi peut-il n'être qu'un pouvoir régulateur ou est-il condamné à être également un pouvoir conservateur? Par leur emprunt, les Brésiliens illustreront précisément le fond du problème.

Deux moments doivent en conséquence être dégagés au Brésil. Le premier concerne le processus constituant (1823-1824), durant laquelle les premiers conservateurs, les coimbrões, s'efforcèrent d'introduire le concept sous l'égide de Constant et surtout de Lanjuinais, en raison du caractère malléable de ses formulations (A). Le second aborde la vie politique des années 1860, date à laquelle la question du pouvoir modérateur apparaît enfin au premier plan ${ }^{32}$; la querelle entre

${ }^{30}$ Chr. Lynch, O Momento Monarquiano. O Poder Moderador e o Pensamento Politico Imperial, thèse, sciences politiques, Rio de Janeiro, IUPERJ, 2007, p. 152 et, de façon générale sur ces influences françaises, pp. 86-142.

${ }^{31}$ Voux d'un solitaire, in Euvres complètes de Jacques-Henri Bernardin de Saint-Pierre, op. cit., pp. 64-65.

${ }^{32}$ Véritable antienne, cette affirmation a été atténuée par la thèse de Christian Lynch. Quoi qu'il en soit, l'étude du pouvoir modérateur présentait peu d'intérêt sous Pedro I, puisqu'il concentra le pouvoir exécutif jusqu'à son abdication en 1831, parfois au nom de l'état d'exception (Chr. Lynch, op. cit., p. 143). La période de régence (1831-1840) est principalement marquée par une opposition radicale visant à maintenir ou à supprimer le pouvoir modérateur ; on assiste cependant à un déplacement sémantique de la notion sur la fin (Ibid., pp. 163-188). Antonio Paim livre une autre explication du dédain pour la question lors des années 1840 et 1850 dans Historia do liberalismo brasileiro, São Paulo, Mandarim, 1998, p. 86, tirant parti de ses propres recherches sur le sujet (voir son article « A discussão do Poder Moderador no Segundo Império », in Curso de Introdução ao pensamento politico brasileiro, éd. UnB, 1982). Le nouvel attrait a pu être motivé par la diffusion d'un abrégé des idées de Constant en 1860 ; il s'agit uniquement de la 
progressistes et conservateurs permettra d'effectuer un bilan de ces influences françaises, en vérité corrompues par un amalgame volontaire visant à introduire les thèses d'Henri Fonfrède. En procédant de la sorte, les conservateurs espéraient renforcer la prérogative de l'Empereur afin de repousser les contestations d'opposants politiques acquis à la cause du parlementarisme anglais (B).

\section{A- La naissance du Pouvoir Modérateur au Brésil (1823-1824) : le moment Lanjuinais ?}

La constitution brésilienne de 1824 consacre au pouvoir modérateur le premier chapitre du Titre V, en le définissant dès l'article 98. Remis à l'empereur, en qualité de chef suprême et de premier représentant de la nation, sa mission consiste à «veiller sur la préservation de l'indépendance, de l'équilibre et de l'harmonie des pouvoirs politiques », ce qui semble en faire un héritier des seules conceptions libérales. Le texte constitutionnel brésilien affiche pourtant rapidement ses ambiguïtés. Si la liste des attributions du pouvoir modérateur, décrite en détail à l'article 101, s'avère assez classique (droits de sanction, de dissolution, de nomination des sénateurs, de grâce...), la principale curiosité provient de l'article 102 qui érige l'empereur au rang de chef du pouvoir exécutif. S'il permet d'inscrire le texte dans la lignée de la tradition initiée par Bernardin de Saint-Pierre et perfectionnée par Lanjuinais, la liste des prérogatives de ce chef du pouvoir exécutif tend rapidement à semer le trouble. D'une part, comme le relevait déjà Silvestre Pinheiro Ferreira ${ }^{33}$, le critère de démarcation entre les attributions du pouvoir modérateur et ceux du pouvoir exécutif semble d'autant plus flou ${ }^{34}$ que la leçon des libéraux français n'est ici guère respectée : la nomination des magistrats, emplois civils, commandants des forces armées et autres diplomates rentre ainsi dans le cadre de l'article 102 dédié au pouvoir exécutif, au même titre que la distribution des honneurs, du droit de guerre et de paix ou encore du droit de négocier les traités, souvent réservés par les libéraux français au seul pouvoir royal. D'autre part, l'embarras est renforcé par une autre interférence liée à des considérations relevant autant du Spirituel que de la sphère privée des individus : en qualité de chef de l'Exécutif, l'Empereur du Brésil a vocation à nommer les évêques sur son territoire et doit surtout s'assurer de la conformité constitutionnelle des décrets des conciles, des lettres apostoliques et de toute autre constitution ecclésiastique, avant de leur concéder l'exequatur. Cette disposition, préservée par la charte portugaise (art. 75), provoquera même l'émoi des rédacteurs du Mémorial catholique qui la percevaient comme une porte ouverte au protestantisme ${ }^{35}$ : les princes lusophones n'étaient-ils pas en effet des rois très chrétiens, ayant pour mission de préserver la religion catholique, comme l'exigeait du reste la propre charte ?

La paternité réservée à Benjamin Constant ne résiste donc pas à une analyse même superficielle : en dehors de la dualité persistante entre pouvoir exécutif et pouvoir modérateur et de l'absence de critère de distinction probant, ce reliquat du césaro-papisme ne pouvait de surcroît lui plaire, lui qui avait longuement insisté sur ce point dès les prémices de son idée sous le Consulat : son pouvoir préservateur n'est pas un pouvoir conservateur et n'a nullement vocation à interférer sur la vie privée des individus, en quelque domaine que ce soit ${ }^{36}$. Ses articles en défense de la

seconde traduction en portugais de ses œuvres, la première datant de 1822, publiée par fragments dans un journal. Voir S. Mota Barbosa, «L’influence de Benjamin Constant sur la pratique politique brésilienne », art. cité, p. 218.

${ }^{33}$ Ce philosophe et politique portugais (1769-1846) fut notamment ministre de la guerre et des affaires étrangères au Portugal dans les années 1820. Forcé de s'exiler en France entre 1823 et 1842, il écrivit alors de nombreux ouvrages de philosophie et de politique d'inspiration libérale, jouissant d'une certaine renommée.

${ }^{34}$ Ces critiques de Pinheiro Ferreira, auxquelles s'ajoutent celles de Bentham, seront évidemment invoquées contre le pouvoir modérateur au Portugal. Voir par exemple l'intervention du député Affonseca, in Diario da Câmara dos Senhores Deputados da Nação Portugueza, legislatura 12, sessão 2, n³7, 20 février 1861, p. 482.

${ }^{35}$ Voir l'article non signé «Chronique de la Révolution du Portugal, de 1820 à 1826. Examen de la constitution portugaise », $3^{\mathrm{ème}}$ article, in Le Mémorial catholique, ouvrage périodique, Paris, $4^{\mathrm{ème}}$ année, 1827, t. VIII, p. 336.

36 «Le pouvoir préservateur, tel que nous l'entendons, n'est donc ni un pouvoir stationnaire qui frapperait d'immobilité l'organisation sociale, ni un pouvoir conservateur qui s'exercerait en faveur d'une masse d'opinions quelconques. Le pouvoir préservateur n'a aucune relation avec les individus; il n'entrave en rien la progression individuelle ; il ne consacre aucune opinion, mais en préservant de leurs froissements réciproques les différentes branches du gouvernement, il contribue au bonheur et au perfectionnement des gouvernés, comme l'architecte qui raffermit tour à 
Charte portugaise de 1826 et, à travers elle, de la constitution brésilienne de 1824, semblent plus vraisemblablement motivés par la conjoncture délicate que par le sentiment d'avoir été totalement compris et/ou approuvé ${ }^{37}$.

L'inspiration du pouvoir modérateur brésilien doit manifestement provenir d'une pluralité de sources. La plupart des études récentes sur le pouvoir modérateur de l'Empire du Brésil présentent pourtant la particularité d'en taire la diversité, en se limitant depuis la fin du XIX ${ }^{\mathrm{e}}$ siècle au seul Benjamin Constant, à qui est offerte la paternité du fameux article de la constitution brésilienne $^{38}$. Pour consacrée qu'elle soit aujourd'hui, en dépit d'évidentes nuances, cette filiation, ou tout du moins l'exclusivité de celle-ci, ne faisait pas l'objet d'une unanimité dans la doctrine politique et juridique de la période impériale. Lors des débats tenus à l'occasion de l'Assemblée constituante, la pluralité des autorités s'affichait de façon ostensible, comme en atteste la récente thèse de Christian Edward Cyril Lynch ; si celui-ci tient à rehausser l'importance des Monarchiens dans le discours des coimbrões ${ }^{39}$, leur vision s'inspire sans contredit, puisque de façon visible donc mesurable, de la pensée politique française de la Restauration.

En 1823-1824, trois acceptions primordiales du pouvoir modérateur peuvent être dégagées $^{40}$. La première appréhendait l'Empereur comme un gouvernant au-dessus des partis, préservant l'intérêt public face aux intérêts particuliers représentés par les partis politiques ou les provinces du Brésil. Cette impartialité, détenue en qualité de pouvoir modérateur et au titre de chef de l'exécutif pour Andrada Machado, lui permettait d'être considéré comme «le mur porteur de la société », placé naturellement «au-dessus des faiblesses et des passions » des députés ${ }^{41}$. Autrement dit, cet «être métaphysique » est le seul habilité « à distinguer le véritable intérêt de la société », et à pouvoir «la guider suivant le bien commun ainsi dégagé» ${ }^{42}$.

La deuxième, prenant en considération l'envergure du Brésil, le dépeignait sous les traits d'un «Argos politique », suivant l'expression de Maciel da Costa : inspiré de Napoléon, le pouvoir modérateur doit tout surveiller, tout observer et tout diriger, secondé comme il se doit par une administration centralisée qu'il convient en conséquence de mettre en place ; organe de la Nation, l'Empereur en est également l'instrument, incarnant, à ce titre, l'intérêt général de façon exclusive.

La dernière, défendue principalement par José Joaquim Carneiro de Campos, le percevait comme un pouvoir d'exception au service du système constitutionnel, une sorte de sentinelle de la nation prévenant toute atteinte contre l'ordre constitutionnel :

«Le monarque constitutionnel, en plus d'être le chef du pouvoir exécutif, reçoit de plus le caractère auguste de défenseur de la Nation; il est sa première autorité vigilante, le gardien de nos droits et de la Constitution. Cette autorité suprême, constituée dans sa personne inviolable et sacrée, et que les publicistes les plus sages

tour ou corrige les diverses parties d'un édifice contribue au bonheur de ceux qui l'habitent, sans gêner leur indépendance, mais en garantissant leur sûreté». B. Constant, Fragments d'un ouvrage abandonné sur la possibilité d'une constitution républicaine dans un grand pays, Paris, Aubier, 1991, p. 417.

37 Telle est l'opinion avancée par S. Mota Barbosa, «L'influence politique de l'œuvre de Benjamin Constant sur la pratique politique brésilienne », art. cité, pp. 224-228.

${ }^{38}$ Pour une étude récente : J. de Scantimburgo, O poder moderador: historia \& teoria, São Paulo, Livraria Pioneira Editora, 1980, notamment pp. 16, 20, 141-142, 195-196. Au contraire, pour N. Nogueira Saldanha, la constitution de 1824, y compris son pouvoir modérateur, tire parti de toutes les branches du libéralisme ; elle serait le fruit d'un «potpourri de influências » (pot-pourri d'influences). Historia das Idéias Politicas no Brasil, op. cit., p. 106. S. A. Malfatti doute également de la paternité de Constant dans sa thèse non publiée ( $O$ poder moderador no pensamento politico brasileiro do seculo XIX, Rio de Janeiro, Université Gama Filho, 1984, VII-233 p.), en grande partie reprise dans son ouvrage Raizes do liberalismo brasileiro, Porto Alegre, Editora Palotti, 1985, notamment p. 157 : il ne s'agirait pas pour lui d'une copie in toto du pouvoir neutre, le pouvoir modérateur brésilien lui semblant plus proche des idées de Silvestre Pinheiro Ferreira sur lequel il insiste longuement. Nous discuterons de cette thèse dans notre seconde partie.

${ }^{39}$ Sa thèse, O Momento Monarquiano, doit se traduire par Le Moment Monarchien suivant ses indications.

${ }^{40}$ Chr.Lynch, O Momento Monarquiano, op. cit., pp. 126-132.

41 Andrada Machado, Anais da Assembléia Constituinte Brasileira, 30 avril 1823. Les citations puisées dans ces annales proviennent de Chr. Lynch, «O Discurso Politico Monarquiano e a Recepção do conceito de Poder Moderador no Brasil (1822-1824) », in Revista de Ciências Sociais, Rio de Janeiro, 2005, vol. 48, n³, pp. 611-654.

${ }^{42}$ Andrada Machado, Anais da Assembléia Constituinte Brasileira., 22 mai 1823. 
de notre temps se sont évertués à distinguer du Pouvoir Exécutif en vertu de leurs différences de nature, d'objectifs et d'attributions ; cette autorité, dis-je, que certains ont appelé pouvoir neutre ou modérateur, et d'autres pouvoir tribun ${ }^{43}$, est essentielle dans les régimes représentatifs $»^{44}$.

Reprenant à son compte les problèmes liés aux empiétements d'un pouvoir sur la sphère de compétence d'un autre pouvoir, Carneiro de Campos louait le pouvoir modérateur, perçu comme le «droit détenu par la Nation d'être protégé par le représentant du bien commun, dans toutes les situations où elle serait privée de ses moyens d'autodéfense face au particularisme des intérêts législatifs ». L'Empereur devient ainsi l'autorité impartiale capable de maintenir l'ordre constitutionnel contre les volontés factieuses et particularistes de ses représentants élus ${ }^{45}$.

Ces défenses, volontairement amphigouriques, du pouvoir modérateur restèrent en vérité minoritaires ; la majorité des membres de l'assemblée constituante, abreuvée d'idées anglaises, aurait indubitablement refusé d'en consacrer l'idée. Au demeurant, les coimbrões ne se souciaient pas, semble-t-il, de la signification réelle du quatrième pouvoir présent chez les libéraux français. Ils en adoptèrent surtout la tactique : les conservateurs brésiliens dissimulaient leurs véritables intentions en recourant à des auteurs susceptibles de plaire à leurs opposants politiques ; stratégie qu'avait déjà employée, avec le même insuccès, Constant en invoquant Clermont-Tonnerre et plus tard Hello, en s'appuyant sur Malouet ${ }^{46}$. Lanjuinais et Benjamin Constant se retrouvent ainsi tout le long du plaidoyer des coimbrões pour des raisons politiques, afin d'offrir un gage de garantie à l'aile gauche de l'assemblée constituante ${ }^{47}$. L'influence anglaise présente en son sein, jugée trop importante et malsaine par D. Pedro, le força à dissoudre l'assemblée et à en exiler certains membres, prétextant que le parlementarisme dont elle faisait preuve menaçait le pays d'anarchie. Prenant alors le serment d'octroyer une constitution, l'Empereur nomma à cet effet un comité de rédaction de dix membres, tous proches du pouvoir (la plupart ministres et militaires), qui bénéficieront tous de ses largesses ${ }^{48}$.

Dans les faits, le processus constituant se révèle étrange, mais permet de dissiper plusieurs zones d'ombre : le principal auteur de la Constitution de 1824 s'avère être Carneiro de Campos, dont les travaux étaient surveillés quotidiennement par D. Pedro en présence des neuf autres conseillers, dont Maciel da Costa ${ }^{49}$. Le pouvoir modérateur du texte définitif s'inspire sans surprise de la vision que défendait Carneiro de Campos lors des séances de la Constituante, même si les autres approches ne sont pas expressément écartées ; les expressions consacrées s'imprègnent, pour leur part, autant de Constant que de Lanjuinais, avec toutefois une nette préférence pour ce dernier, compte tenu de la dualité pouvoir modérateur/pouvoir exécutif finalement choisie. Ses formules équivoques permettaient, en outre, de répondre de manière positive aux ambitions des coimbrões, soucieux d'entrouvrir une porte au renforcement des pouvoirs de l'Empereur ${ }^{50}$; elles serviront d'appui au modèle saquarema en vigueur de 1837 à 1877 . Ce système politique se caractérise par

\footnotetext{
${ }^{43}$ La référence à Rousseau est tacite. Mais le citoyen de Genève défendait-il réellement la même idée ? Cf. P. Rolland, «La préservation des institutions politiques est-elle une utopie? sur le Tribunat de Jean-Jacques Rousseau », in Utopies. Entre droit et politique. Etudes en hommage à Claude Courvoisier, éd. univ. de Dijon, 2005, pp. 51-66.

${ }^{44}$ Carneiro de Campos, 1823, Diario da Assembléia Geral Constituinte e Legislativa do Império do Brasil, vol. I, p.300

${ }^{45}$ Carneiro de Campos, Anais da Assembléia Constituinte Brasileira, 28 juillet 1823.

${ }^{46}$ Voir La Minerve française, t. V, février 1819, p. 77 où Constant reconnaît s'être appuyé sur «quelques expressions assez vagues » de Clermont-Tonnerre afin de bénéficier de la protection que son nom évoque aux esprits modérés.

${ }^{47}$ Voir Chr. Lynch, O Momento Monarquiano, op. cit., pp. 125-126.

${ }^{48}$ Leurs noms sont disponibles dans l'ouvrage de Ch. Reybaud, Le Brésil, Paris, Henri Plon, 1856, p. 52.

${ }^{49}$ Chr. Lynch, O Momento Monarquiano, op. cit., pp. 135-137. Sur cette constitution, voir également, en dépit de certaines informations caduques, N. Nogueira Saldanha, Historia das Idéias Politicas no Brasil, op. cit., pp. 103-138.

${ }^{50}$ Chr. Lynch, O Momento Monarquiano, op. cit., pp. 140-141. Nous le réfutons en revanche sur leur emprunt aux formules des Monarchiens : Lanjuinais fournissait aux coimbrões une assise suffisamment malléable pour leur plaire. Son principal argument en faveur de cette thèse, à savoir que la Constitution brésilienne offre le pouvoir modérateur au «premier représentant de la nation», ne tient pas : loin de leur être exclusive, la tournure retenue consacre en vérité une formule de Lanjuinais (Constitutions de la nation française, avec un essai de traité historique et politique sur la Charte, et un recueil de pièces corrélatives, Paris, Librairie constitutionnelle de Baudoin frères, 1819, tome I, p. 191).
} 
l'hégémonie du Pouvoir Modérateur, compris comme un pouvoir exceptionnel de dissolution et de nomination, secondé par un gouvernement de cabinet qu'il supervise. Dans cette configuration, l'assemblée législative se contente d'être une arène d'apprentissage et délivre ses conseils ${ }^{51}$.

Le jeu de dupes auquel se sont livrés les conservateurs brésiliens nous incite à livrer un premier bilan des influences françaises, cantonné ici au processus constituant. En dépit des apparences, les Brésiliens n'ont pas pris part au débat propre aux libéraux de la Restauration ; la récente thèse de $\mathrm{C}$. Lynch, perpétue d'ailleurs cette vision tronquée du sujet en assimilant à tort les représentations du pouvoir royal de Constant, Lanjuinais, Rossi et Chateaubriand ${ }^{52}$. Or, les différences sont pour le moins marquées, même en écartant l'auteur de la Monarchie selon la Charte de la discussion. Certes, le pouvoir royal actif et modérateur prôné par Lanjuinais et par Rossi ne se différenciait pas de la thèse de Constant par son but apparent. Si la paix représente également un objectif de premier ordre, elle n'est plus qu'un préalable nécessaire à la satisfaction des besoins matériels des Modernes; elle impose en conséquence la conservation de l'Etat, ce qui implique de pallier ses dysfonctionnements internes par l'entremise d'un pouvoir régulateur, suivant le sens révolutionnaire, c'est-à-dire limité à la sphère constitutionnelle. Le roi ne doit donc pas s'occuper de tout; il doit laisser l'homme moderne vaquer à ses occupations, afin qu'il puisse atteindre par ses propres moyens le bonheur qu'il recherche. Ainsi neutralisé dans la sphère sociale, le roi neutralise également les ambitions, ou plutôt nous préserve des conflits de succession, que susciterait un trône vacant suivant les convictions partagées, depuis les auteurs de la Renaissance italienne, sur les monarchies nouvelles ou électives.

Une divergence de fond existe néanmoins et reposait autant sur la neutralité que sur le concept de pouvoir. Dans une société imprégnée de façon indélébile du triptyque hérité de Montesquieu (pouvoirs exécutif, législatif, judiciaire), la notion même de pouvoir royal est sujet à controverse. De fait, celle-ci est peu employée des libéraux et même combattue ${ }^{53}$, soulignant l'opposition entre une conception fidèle à la «division métaphysique » de Montesquieu ${ }^{54}$ et une autre, plus novatrice, qui s'en écarte quelque peu en introduisant un véritable quatrième pouvoir. Loin de n'être qu'une question de terminologie comme l'estimait Rossi ${ }^{55}$, la différence est profonde entre ces deux options. La première, incontestablement majoritaire, ne propose qu'un découpage singulier des fonctions de l'Etat. En dépit de leur reconnaissance, les trois pouvoirs n'entraînent donc pas une séparation fonctionnelle des pouvoirs ${ }^{56}$. C'est un système d'équilibre des pouvoirs qui est ainsi mis en place, le roi se réservant une part de chacune des trois fonctions, destinée à en assurer la marche : droit de grâce pour le pouvoir judiciaire, droit de nomination des pairs et droit de sanction pour le pouvoir législatif, droit de dissolution et droit de nomination des ministres pour le pouvoir exécutif. Il ne formerait donc pas un pouvoir à part entière, mais concentrerait en lui une partie des autres ; ceci le placerait au cœur de l'édifice institutionnel, en lui conférant les missions intellectuelles tout en l'écartant de l'action, sauf en cas de nécessité. Constant en revanche tend à soustraire définitivement les mêmes prérogatives aux trois pouvoirs afin d'en faire naître un quatrième doté d'une essence, d'une métaphysique qui lui est propre et doté, à ce titre, d'attributs

\footnotetext{
${ }^{51}$ Nous reprenons la définition de Chr. Lynch, O Momento Monarquiano, op. cit., p. 209.

${ }^{52}$ Chr. Lynch, Ibid., p. 83.

${ }^{53}$ Par exemple, par Ch.-G. Hello, Essais sur le régime constitutionnel, op. cit., pp. 91-92.

${ }^{54} \mathrm{C}$ 'est ainsi qu'elle est comprise à l'époque, comme en atteste J. de Sismondi : «L'on est convenu d'appeler principe, en théorie politique, la division métaphysique des pouvoirs exécutif et législatif, dont l'un est attribué au gouvernement, l'autre au peuple ». Examen de la constitution françoise, Paris, Treuttel et Würtz, 1815, p. 52. Le terme symbolise une différence d'essence entre ces deux pouvoirs.

${ }_{55}$ P. Rossi, Cours de droit constitutionnel, op. cit. , tome IV, pp. 222-223.

${ }^{56}$ La séparation fonctionnelle des pouvoirs, également nommée principe de spécialisation dans une fonction unique, implique l'idée qu'un organe ou groupe d'organes est le détenteur exclusif de l'intégralité d'une fonction étatique. Il forme à ce titre un pouvoir qui n'a aucune part à l'exercice d'une fonction dévolue à un autre pouvoir. Voir M. Lahmer, La constitution américaine dans le débat français 1795-1848, Paris, L'Harmattan, 2001, p. 8 et suivantes, et, d'une façon générale, M. Troper, La séparation des pouvoirs et l'histoire constitutionnelle française, Paris, L.G.D.J., 1980.
} 
eux-mêmes naturellement distincts et propres à cette fonction ; ainsi préserve-t-il son indépendance tout en limitant autant que possible le phénomène d'érosion du pouvoir royal, en ne le soumettant qu'aux flétrissures du progrès et non plus au rapport de force qui s'installerait inévitablement entre lui et les autres organes (parlement, ministère, cours de justice) quant à l'emploi des prérogatives en cause. A ce titre, le pouvoir royal doit se démarquer totalement du pouvoir ministériel ${ }^{57}$, esquivant du même coup les craintes liées à une possible confusion des pouvoirs entre les mains du $\mathrm{Roi}^{58}$. Cette séparation implique de reporter la responsabilité sur les seuls ministres, empêchant le monarque de faire le moindre acte sans leur signature ${ }^{59}$, y compris a priori ceux relevant des prérogatives du pouvoir neutre.

Pour sa part, Lanjuinais refusait de faire du roi un pur pouvoir neutre, désireux au contraire de voir en lui un pouvoir en quelque sorte dualiste, modifiant sa nature intrinsèque au gré de la situation qu'il s'apprêtait à affronter ou de la prérogative qu'il souhaitait employer :

«Pour qu'il y ait une liberté régulière, il faut une autorité médiatrice directoriale, modératrice, neutre à certains égards, absolue sous d'autres rapports, enfin irresponsable, une autorité qui prévienne ou termine toute lutte pernicieuse, qui entretienne ou rétablisse l'harmonie nécessaire entre les grandes autorités. Voilà ce que le Roi seul effectue $[\ldots] »^{60}$.

Si neutralité il y a, celle-ci ne s'exprime au mieux que dans certaines attributions, dans certains cas délimités, tandis que dans d'autres, le pouvoir royal se révèle encore actif. L'absence de réelle neutralité du roi chez Lanjuinais est notamment prouvée par le rôle qu'il lui fait jouer dans le pouvoir exécutif : loin de le soustraire de cette fonction, Lanjuinais en fait une partie intégrante, non sans effectuer une subtile distinction entre pouvoir exécutif général, attribut exclusif du roi, et pouvoir exécutif spécial, conféré aux ministres :

«[...] le pouvoir exécutif, pris au sens le plus général, est divisé, de fait, entre le Roi, qui nomme et révoque ses ministres, et les ministres eux-mêmes, qui, étant responsables, pour que le Roi soit inviolable et le despotisme presque impossible, constituent entre eux seuls, sous ce rapport de responsabilité, le pouvoir exécutif spécial, à certains égards, distingué très réellement du pouvoir royal ${ }^{61}$.

Une telle démarcation pourrait aisément tenir du décorum. En effet, Lanjuinais ne s'appesantit guère sur la question, sauf à revenir sur le rôle du roi au sein du Conseil des ministres pour un résultat révélateur. En imposant le culte du secret, il semble trahir sa volonté de brimer le pouvoir royal à l'ombre de machinations subreptices, laissant au moins entrouverte la porte qui permettra à Adolphe Thiers de défendre en 1830 son aphorisme «Le roi règne et ne gouverne pas» :

«Ils [les ministres] peuvent être dirigés par le Roi, ou ne l'être pas, l'être en tout, ou à l'égard de peu d'objets ; l'être par présomption seulement, ou l'être au sens le plus rigoureux et presque sans exception.

\footnotetext{
57 « Mais on perd cet immense avantage, soit en rabaissant le pouvoir du monarque au niveau du pouvoir exécutif, soit en élevant le pouvoir exécutif au niveau du monarque. Si vous confondez ces deux pouvoirs, deux grandes questions deviennent insolubles : l'une, la destitution du pouvoir exécutif proprement dit, l'autre la responsabilité ». Principes de politique (version 1815), in B. Constant, Ecrits politiques, op. cit., p. 328.

${ }^{58}$ Comme le répétera Charles Dunoyer : «Il est d'autant plus nécessaire que le roi, souverain modérateur de tous les pouvoirs, délègue la puissance exécutive [...] : si le roi restait confondu avec elle, il deviendrait nécessairement suspect de vouloir attirer à lui toute l'autorité, et changer son rôle d'arbitre et de régulateur suprême de tous les pouvoirs en celui de maître absolu de tous les pouvoirs ». Ch. Dunoyer, article « De la royauté, ou de la première magistrature de l'Etat dans une monarchie constitutionnelle », in Le Censeur, ou Examen des actes et des ouvrages qui tendent à détruire ou à consolider la constitution de l'Etat, Paris, 1815, tome V, pp. 49-50.

${ }^{59}$ «Le pouvoir ministériel est si réellement le seul ressort de l'exécution dans une constitution libre, que le monarque ne propose rien que par l'intermédiaire de ses ministres : il n'ordonne rien, que leur signature n'offre à la nation la garantie de leur responsabilité ». Principes de politique (1815), in B. Constant, Ecrits politiques, op. cit., p. 333.

${ }^{60}$ J.-D. Lanjuinais, Constitutions de la nation française, op. cit., tome I, p. 198.

${ }^{61}$ Ibid., tome I, p. 186.
} 
Mais tout cela doit être le secret du Roi ; nul n'a le droit de s'y immiscer ; il suffit que les ministres soient responsables $»^{62}$.

Modérateur et arbitre, gardien de la Charte et des droits publics ${ }^{63}$, le roi était uniquement subordonné dans ses prérogatives à la volonté générale; il les exerce donc en propre, tout en se réservant une part volontairement indéfinie de l'Exécutif.

Cette zone d'ombre a précisément plu aux conservateurs brésiliens. Loin d'adhérer aux préceptes de Constant, qu'ils n'ont sans doute ni compris ni même voulu comprendre, ceux-ci s'ingéniaient plutôt à reconsidérer le gouvernement représentatif afin d'éviter de consacrer le régime parlementaire. Loin de minimiser l'influence intellectuelle des théoriciens français, ces considérations devaient au contraire la consolider d'une façon inattendue. La France de la Restauration offrait en effet un riche débat sur les contours du gouvernement représentatif qu'il s'agissait de refondre à la suite des soubresauts révolutionnaires en renforçant la prérogative royale. Or, pour pouvoir comprendre la genèse du pouvoir modérateur brésilien, il faut mesurer la portée de ce débat français qui non seulement a été suivi, mais représente de plus la toile de fond du projet constitutionnel impérial. Christian Lynch en a déduit la victoire du programme monarchien ; mais s'il existe peut-être un «moment monarchien » comme le suggère le titre définitif de sa thèse, celui-ci se repère moins dans la notion de pouvoir modérateur que dans celle de gouvernement représentatif. En estimant que les Monarchiens sont les pères du pouvoir modérateur brésilien, $\mathrm{C}$. Lynch nous semble dans l'erreur tant leurs théories sont, sur ce point, peu probantes. Nous n'en retiendrons que l'exemple emblématique de Stanislas de Clermont-Tonnerre. Celui-ci distingue bien, dans le roi, le «pouvoir royal » du pouvoir exécutif ${ }^{64}$; mais ce « pouvoir royal » ne se réfère nullement à un pouvoir régulateur : non seulement ce rôle est expressément dévolu à une chambre haute ${ }^{65}$, mais, de plus, l'auteur entend par « pouvoir royal » une fonction de « co-législateur » ${ }^{66}$. En revanche, la notion de gouvernement représentatif, souvent proche de gouvernement mixte, a pu effectivement tirer parti de la diffusion des discours des Monarchiens au Brésil.

Nous serions toutefois tentés de n'y voir qu'une influence subsidiaire, transitant à travers deux figures marquantes de la Restauration qui, à certains égards, peuvent se revendiquer du mouvement monarchien : Royer-Collard ${ }^{67}$, dont des extraits de discours sont traduits en portugais, et Montlosier, qui apparaît de façon notable dans les débats de l'Assemblée constituante brésilienne $^{68}$. Parmi les trois approches du pouvoir modérateur au Brésil, nous nous sommes peu appesantis sur la première, défendue par Andrada Machado. Or, sa perception du pouvoir impérial ressemble étrangement au roi arbitre d'Ancien Régime ${ }^{69}$. Ce rapprochement n'est pas hasardeux et ne présente rien de fortuit. En cherchant à donner un nouveau souffle aux institutions, Montlosier et

\footnotetext{
${ }^{62}$ Ibid., t. I, p. 201. Son approche évoque celle de Necker: cf. H. Grange, Les idées de Necker, Paris, Librairie C. Klincksieck, 1974, p. 296. Dupin défendra auprès de Louis Philippe l'idée que les relations entre le roi et ses ministres devaient être une «affaire d'intérieur, entre eux et lui » (Mémoires de M. Dupin, Paris, Henri Plon, 1855-1861, tome III, pp. 311-312. Il souligne). S'il tempère son opinion, n'oublions pas que Dupin adhérait à l'apophtegme de Thiers.

${ }^{63}$ Lanjuinais en fait le critère de sa définition du pouvoir royal : Constitutions de la nation française, op. cit., t. I, p. 191.

${ }^{64}$ Analyse raisonnée de la constitution française, in Euvres complètes de Clermont-Tonnerre, Paris, Letellier, an III, tome IV, p. 392.

${ }^{65}$ Ibid., tome IV, pp. 250 et 316.

${ }^{66}$ Ibid., tome IV, p. 393.

67 Voir J.-Fr. Jacouty, «Tradition et modernité dans la pensée politique de Royer-Collard », in Revue française d'histoire des idées politiques, $\mathrm{n}^{\circ} 27,2008$, pp. 75-110.

${ }^{68}$ Christian Lynch affilie Montlosier aux Monarchiens. Une chose est sûre : cet auteur a eu de l'influence au Brésil.

${ }^{69}$ Fr. Olivier-Martin insiste dessus (L'absolutisme français, Paris, L.G.D.J., coll. reprints, 1997, pp. 264 et 293-295) : «Le roi, placé par sa fonction héréditaire au-dessus des ordres, des corps et des pays, définit le bien commun du royaume, qui est au-dessus de tous ces biens communs subordonnés. De son point de vue dominant, il détermine les sacrifices que chacun doit faire et arbitre sous cet angle les différends qui les oppose». Ibid., p. 264. Le roi arbitrait donc plus qu'il ne commandait; son but est d'assurer ou de rétablir l'union. En conséquence, le roi agissait le plus souvent sur requête que de son propre mouvement, renouant ainsi avec la première définition de l'arbitre. Ibid., p. 283.
} 
Royer-Collard renouvelaient cette approche du pouvoir royal. Les partisans de cette tendance en faisaient l'arbitre d'une représentation nationale certes remodelée, celle-ci ne pouvant plus être divisée en ordres, mais qui ne parviendrait pas à représenter autre chose que des intérêts de classe. Royer-Collard clarifiait l'idée en y associant l'analogie du Roi, image de Dieu ; le propre du Roi consiste ainsi à modérer les revendications des deux clans opposés depuis la Révolution, à arbitrer les intérêts se manifestant au sein des assemblées, afin de permettre la réunion de la grande famille chrétienne dans l'optique d'un salut au moins terrestre :

«Heureuse, dans son malheur, une nation qui, réduite par des attentats et des revers inouïs à ce désordre où les lois s'arrêtent comme d'elles-mêmes, trouve dans son prince, image de la Providence, un modérateur élevé au-dessus de toutes les passions, capable de rattacher les événements à leurs causes, et de découvrir dans la nature des maux celle des remèdes qu'ils sollicitent ; un juste arbitre de la sévérité et de la clémence, qui, après avoir fait concourir l'un et l'autre au salut de l'Etat, n'étudie plus dans le passé que la leçon de l'avenir, et se hâte d'appeler tous les intérêts de la grande famille à une réconciliation solennelle et durable $»^{70}$.

Ces autorités furent-elles oubliées au lendemain de la promulgation de la Constitution de 1824 qui consacrait les expressions de Constant et de Lanjuinais ? Rien n'est moins sûr. Pour mieux nous en rendre compte, il peut être utile de reprendre la distinction effectuée notamment par Georges Vedel ${ }^{71}$ entre « auteur» et « écrivain » de la constitution. Pour résumer, l'auteur de la constitution désigne l'autorité chargée de la sanctionner, et le ou les écrivain(s) ne sont autres que les personnes ayant participé à la rédaction de la constitution ou l'ayant adoptée sans la sanctionner. Or, si Carneiro de Campos fut le principal écrivain de la constitution, consacrant les expressions de Constant et de Lanjuinais qu'il avait défendues, il n'en fut pas l'auteur. La querelle des influences prend dès lors une tournure inattendue, puisqu'il faut en amont identifier le véritable auteur de cette constitution. Entreprise qui se révèle bien moins aisée que prévu : l'empereur est une solution faussement évidente qui ne résiste pas à une analyse socio-politique du Brésil. Un pays principalement dominé par des grands propriétaires hostiles au pouvoir central pouvait-il se contenter d'un pouvoir modérateur aux aspirations purement constitutionnelles ou accepter sans regimber la tutelle d'un Argos politique ? Assurément pas. Une analyse totalement renfermée sur le droit constitutionnel n'aboutirait pas. Au demeurant, Charles Morazé, sur un ton sarcastique, nous avait déjà prévenu de cette réalité et des limites d'une approche strictement juridique :

« «Pouvoir Modérateur»! C'est le pouvoir de rappeler à la majorité parlementaire qu'elle ne tient son autorité que de sa soumission aux ordres des seigneurs de la terre, des barons du café (ou du sucre, ou du coton). C'est le pouvoir de rappeler aux ministres que l'Etat n'est que façade fragile et que l'immense Brésil est voué à la dislocation si les chatouilleux pouvoirs de fait, locaux, sentent trop vivement l'emprise de l'administration de Rio ou, comme on disait, de la Cour ${ }^{72}$.

Le lecteur avisé saurait toutefois reconnaître que ce rôle, loin de ne servir qu'à « sauver les apparences ${ }^{73}$, doit présenter une dimension conservatrice propre à la rapprocher du fond des thèses défendues par Royer-Collard voire Bonald ; il devinerait également la fracture existant entre un texte constitutionnel trop ambitieux et une réalité sociale archaïque, marquée par l'hostilité des classes dirigeantes contre toute bureaucratie. Dans ces conditions, peut-on avouer qu'une analyse "classique », s'évertuant à déceler l'influence intellectuelle de tel auteur sur un autre producteur d'idées, ne produirait que des conclusions limitées et doit être supplantée par la recherche d'une influence politique, celle d'un homme sur un milieu social, ici les propriétaires fonciers ? L'entreprise n'en serait que plus hasardeuse, mais permettrait de récuser toute reconnaissance de

\footnotetext{
${ }^{70}$ Discours de Royer-Collard sur la loi d'amnistie (1815), in Pr. de Barante, La vie politique de M. Royer-Collard. Ses

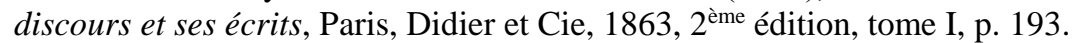

${ }^{71}$ Neuf ans au conseil constitutionnel. Entretien avec Georges Vedel in Le Débat, mai/août 1989, n55, p. 53.

${ }^{72}$ Ch. Morazé, Les trois âges du Brésil. Essai de politique, op. cit., p. 81.

${ }^{73}$ Ibid., p. 82.
} 
paternité au profit de simples présomptions voire d'une paternité multiple ${ }^{74}$. Précisément, c'est en prenant en considération la fragilité intrinsèque d'un pays gigantesque comme le Brésil que les conservateurs vont, dès le départ, saisir les limites d'une approche typiquement constitutionnelle et récuser à demi-mot les thèses défendues par les libéraux français. Que Lanjuinais et Constant aient eu, à un moment donné, une influence intellectuelle semble acquis. En revanche, que celle-ci, futelle implicitement consacrée par la Constitution de 1824, ait réellement marqué la pratique politique brésilienne semble plus douteux. Les approches du pouvoir conservateur semblaient mieux adaptées. Or, c'est en découvrant la pensée d'un autre libéral conservateur, Henri Fonfrède, que la droite brésilienne cherchera à redéfinir les contours du pouvoir modérateur.

\section{B- La pratique politique brésilienne et le débat des années 1860 : le moment Fonfrède?}

Si l'influence de Lanjuinais est aujourd'hui tombée dans l'oubli, elle ne l'était pas encore totalement à l'occasion du grand débat des années 1860. Le professeur de droit Braz Florentino Henriques de Souza, dans son essai sur le pouvoir modérateur de 1864, défendait en vérité la même thèse que la nôtre. Proche des milieux conservateurs, ceux-là même qui contribuèrent à donner naissance à la Constitution octroyée de 1824, le futur gouverneur de l'Etat du Maranhão rappelait que Lanjuinais était lui-même cité, dès le départ, par les défenseurs de l'idée du pouvoir modérateur $^{75}$, avant de livrer les clefs de l'analyse des célèbres articles 98 et 102 de la constitution brésilienne: le pouvoir modérateur qui y est décrit dérive non pas de la théorie de Benjamin Constant, qui repousse formellement la cohabitation, en de mêmes mains, des pouvoirs modérateur et exécutif, mais bien de celle de Jean-Denis Lanjuinais ${ }^{76}$, auteur alors au moins aussi lu, mais dont la renommée se fanera progressivement au point de disparaître des mémoires ${ }^{77}$.

Si la démonstration est, sur ce point, parfaitement menée, la tournure politique de l'œuvre de Henriques de Souza interpelle. Car, en recourant à Fonfrède et même à Bonald, sa perception du pouvoir modérateur ne pouvait décemment se renfermer dans le champ strictement constitutionnel. Du reste, le professeur de droit ne s'en cachait pas, comme en atteste sa propre définition de ce pouvoir, qui se veut tirée de son analyse de la constitution :

«Le Pouvoir Modérateur, c'est la plus haute expression de la souveraineté nationale qui chercherait sagement à se préserver contre ses propres dérives ; c'est la volonté suprême de la société, désireuse avant tout d'assurer son existence et sa conservation ; c'est, en un mot, la royauté ou la monarchie. [...] tel est le destin de cette merveilleuse institution, qui [...] nous apparaît toujours absolument nécessaire aux peuples, comme principe conservateur par excellence des sociétés, comme l'ancre de salut, réservée par la Providence aux nations menacées, ou déjà battues par la tourmente révolutionnaire ${ }^{78}$.

Apparaît ainsi ouvertement l'intérêt politique de ce soi-disant pouvoir modérateur. Henriques de Souza a beau louer en Constant la meilleure définition du quatrième pouvoir ${ }^{79}$, il se montre, sur le terrain institutionnel, bien plus séduit par l'approche de Lanjuinais d'un pouvoir

\footnotetext{
${ }^{74}$ Pour un aperçu général du problème, voir P. Rolland, «A propos de Proudhon : une querelle des influences », in Revue française d'histoire des idées politiques, ${ }^{\circ} 2$, 1995, pp. 275-300.

${ }^{75} \mathrm{Br}$. Fl. Henriques de Souza, Do poder moderador, op. cit., p. 17. Il fut gouverneur sous l'étiquette conservatrice.

${ }^{76} \mathrm{Ibid}$., notamment p. 30 où il établit un parallélisme convaincant entre les formulations de la constitution et les propos de Lanjuinais.

${ }^{77}$ Ceci explique en partie les réticences des contemporains brésiliens à le reconnaître, comme Scantimburgo, qui a pourtant bien lu et manifestement apprécié l'ouvrage de Henriques de Souza. La paternité de B. Constant représente aujourd'hui une sorte de titre de gloire du constitutionnalisme brésilien (et portugais) qu'il convient de préserver... Malgré tout, l'ouvrage dirigé par le constitutionnaliste W. Costa Porto, O poder legislativo : curso, departamento de Impr./Nacional, 1981, vol. 2, p. 108, attribue à Constant et à Lanjuinais une paternité conjointe, exemple qui reste néanmoins isolé compte tenu de l'oubli de la diversité des sources françaises. Une autre explication de cet oubli peut provenir de l'usage qu'en fait Henriques de Souza afin de soutenir son approche autoritaire du pouvoir modérateur.

${ }^{78} \mathrm{Br}$. Fl. Henriques de Souza, Do poder moderador, op. cit., p. 16.

${ }^{79}$ Ibid., p. 4.
} 
royal neutre sous certains aspects, mais surtout absolu dans d'autres ${ }^{80}$, et de toute manière irresponsable. Mais il s'extirpe rapidement des convictions de ces libéraux classiques afin de rejoindre les considérations des conservateurs et des réactionnaires : ce qui l'intéresse, c'est bien ce principe conservateur des sociétés qui vise à maintenir l'unité et l'harmonie de la société, en s'assurant de la bonne entente des pouvoirs; des pouvoirs qu'il n'envisage alors plus sous l'angle purement constitutionnel, mais sous l'angle social : ce sont les «pouvoirs sociaux » que le pouvoir de l'Empereur doit surveiller pour le bien être du Brésil ${ }^{81}$. Autrement dit, ce pouvoir ne sert qu'à une seule chose, à savoir prévenir l'anarchie ou, ce qui semble revenir au même, les relents de la Révolution française et de la pensée moderne. Aussi devient-il nécessaire d'instaurer une hiérarchie entre les pouvoirs de l'Etat, l'Empereur représentant justement, en tant que pouvoir modérateur, le chef suprême de l'organisation politique, mais aussi, et surtout, «a pendula do grande mechanismo social $\gg^{82}$ (le pendule du grand mécanisme social), preuve de son attrait pour les questions sociales. $\mathrm{Au}$ demeurant, ce professeur de droit n'était pas isolé dans son interprétation. Son orthodoxie ne fait même aucun doute : la plupart des exégètes de la constitution de 1824 au XIX ${ }^{\mathrm{e}}$ siècle désignent le pouvoir modérateur sous le nom de «pouvoir royal ou conservateur », voyant en lui «l'inspection suprême de la nation ${ }^{83}$. Cette expression, souvent citée, provient d'ailleurs de la plume de José Antonio Pimenta Bueno, marquis de São Vicente ${ }^{84}$, un libéral conservateur (Partido Conservador) qui endossera la fonction de président du Conseil en 1870.

$\mathrm{Au}$ nom de cette mission conservatrice, l'Empereur doit impérativement être qualifié de représentant de la Nation, Henriques de Souza écartant, après s'être longuement attardé dessus, le débat classique de 1791 entre Thouret, Barnave et Roederer ${ }^{85}$; sans ce statut, les différents intérêts qui circulent dans la société ne sauraient être représentés et risqueraient, à terme, de rompre l'équilibre. Apparaît ainsi, étayé par le rôle assumé par D. Pedro II au long de son règne, la dimension « civilisatrice » du pouvoir modérateur ${ }^{86}$ : celle d'un pouvoir chargé d'institutionnaliser deux partis politiques, représentant chacun l'un des deux intérêts dominants présents au sein de toute société (innovation contre conservation), tout en préservant celle-ci de l'implosion ${ }^{87}$.

En conséquence, Henriques de Souza devait finalement s'inspirer bien plus de Fonfrède, auteur qu'il approuve tout le long de son ouvrage et qu'il cite régulièrement in extenso. Ceci le conduit à réfuter ses adversaires de la monarchie de Juillet, qualifiés d'anarchistes enfantés par la Révolution, en particulier Hello et Berriat-Saint-Prix. Le professeur brésilien critique ainsi non seulement l'infaillibilité du roi, popularisée par l'aphorisme the king can do no wrong, produit de l'impiété des rois anglais suivant la remarque de Donoso Cortes qu'il se plaît à remémorer ${ }^{88}$, mais encore la descendance intellectuelle de l'idée, à savoir l'apophtegme de Thiers :

«Cette étrange doctrine, où l'infaillibilité offerte au monarque, et son corollaire, l'inviolabilité, servent de justification dérisoire à son statut avilissant, liant impassibilité et inaction, dans lequel il se cantonne, n'est

\footnotetext{
${ }^{80}$ Ibid., p. 11. Il souligne d'ailleurs le mot « absolu » de la définition de Lanjuinais afin de marquer son approbation.

${ }^{81}$ Ibid., p. 12. C'est également cet aspect qui plaît à J. de Scantimburgo, mais il convient de le noter : presque tous les auteurs brésiliens contemporains sont de cet avis, quitte à interpréter de façon curieuse la théorie de Constant comme le fait A. Arinos de Melo Franco, Estudos de Direito Constitucional, op. cit., p. 246 et s.

${ }^{82} \mathrm{Br}$. Fl. Henriques de Souza, Do poder moderador, op. cit. , p. 25. Il s'appuie ici sur des pensées de Donoso Cortes, qui, dans le passage visé, cite Bonald.

${ }^{83}$ Ce que souligne N. Nogueira Saldanha dans son Historia das Idéias Politicas no Brasil, op. cit., p. 122.

${ }^{84}$ J. A. Pimenta Bueno, Direito publico brasileiro e Analise da Constituição do Império, Rio de Janeiro, Tipographia de J. Villeneuve, 1857, p. 204. L'œuvre en question est considérée comme la première étude constitutionnelle notable du Brésil. Dans la bibliographie très restreinte de cet ouvrage (pp. 17-18), figure l'ensemble des publicistes français ayant étudié la question du pouvoir modérateur (au sens large) : Constant, Lanjuinais, Isambert, Fritot...

${ }^{85} \mathrm{Br}$. Fl. Henriques de Souza, Do poder moderador, op. cit., pp. 32-39. Sur le débat français de 1791, voir P. Brunet, Vouloir pour la Nation. Le concept de représentation dans la théorie de l'Etat, Paris, L.G.D.J, 2004, pp. $221-253$.

${ }^{86}$ Sur ce point : Heitor Lyra, Historia de Dom Pedro II, São Paulo, Companhia Editora Nacional, 1938, tome II, p. 507.

${ }^{87}$ Pour J. de Scantimburgo, cette dimension a permis de sauver le Brésil impérial des déchirements internes, à la différences des autres Etats d'Amérique latine et du Brésil lui-même depuis l'avènement de la République en 1889.

${ }^{88} \mathrm{Br}$. Fl. Henriques de Souza, Do poder moderador, op. cit., pp. 54-55.
} 
rien de plus que l'appendice obligatoire et l'explication légitime de la théorie contenue dans une autre maxime politique tout aussi fameuse et obscure, selon laquelle « le roi règne et ne gouverne pas » : maxime révolutionnaire et ultramontaine, suivant l'illustre marquis de Valdegamas [Donoso Cortes], employée dans le but de faire comprendre que le roi n'est rien, ni au sein de la société, ni en politique [...]»>

Sa prédilection pour l'approche de Lanjuinais provient de formulations qui, prises hors contexte, paraissent effectivement favorables au roi. Le libéral français représente pourtant le patron, certes prudent, du pouvoir modérateur de ces «ultra » libéraux abreuvés d'idées anglaises et qualifiés d'anarchistes par le juriste brésilien. A l'instar des coimbrões, Henriques de Souza profite surtout des ambiguïtés de Lanjuinais pour assurer la défense d'un pouvoir modérateur qui se doit également de gouverner : gouverner consiste selon lui à conserver la direction intellectuelle du gouvernement et à se faire seconder pour l'exécution de ces ordres. Autrement dit, même si l'Empereur incarne le pouvoir modérateur, il peut et même doit régner et gouverner ${ }^{90}$; l'équilibre des pouvoirs en dépend, et plus encore l'avenir de l'Etat et de la société qu'il abrite, au cœur des considérations du professeur brésilien. Le supposé déclin moral du Brésil des années 1860 incitait les conservateurs à réserver à l'Empereur un pouvoir fort, susceptible selon eux de purger le pays ${ }^{91}$.

Ces derniers renouaient ainsi avec les thèses du pouvoir conservateur, en se référant autant à Fonfrède qu'à Bonald. De surcroît, ils en adoptaient le constat alarmant. Devant l'état jugé préoccupant de la société française au sortir de la Révolution, minée par le déchirement des groupes sociaux, par la diversité des intérêts et l'indifférentisme religieux, il paraissait souhaitable de confier au Roi une mission conservatrice : en arbitrant les conflits entre les diverses parties de la société (bourgeoisie, prolétariat...) et plus exactement ce que l'on surnomme alors les «deux France » (partisans et ennemis de la Révolution), le pouvoir royal assurerait la pérennité du pays et de ses institutions, quitte à intervenir dans des domaines touchant à la sphère privée des individus (éducation, religion...). Les courants ultraroyalistes et les milieux conservateurs, attachés aux bons acquis de la Révolution, ne présentaient certes pas une solution commune, nuance que n'ont pas perçu les conservateurs brésiliens. Sans rentrer dans les détails, les ultras jugeaient que le roi doit essentiellement assurer la paix en ce qu'elle offre aux hommes la possibilité de travailler pour leur salut: il doit préserver la société telle qu'elle fut conçue à l'origine par Dieu ${ }^{92}$. Pour les conservateurs, au contraire, le pouvoir royal est chargé de veiller à la croissance saine de la société, comprise dorénavant suivant son acception réaliste et donc évolutive, terreau de leur concept de civilisation. Pour autant, dans les deux cas, le rôle du roi se révèle essentiellement gouvernemental et paradoxalement assez limité, puisque tout a déjà été créé soit par Dieu ${ }^{93}$ soit par la Charte. Il vise d'une part à corriger les individus ayant erré ou étant susceptibles de le faire, justifiant dès lors une relative immixtion dans leur vie privée. Ce rôle de «directeur moral de la société », d'après

\footnotetext{
${ }^{89}$ Ibid., pp. 56-57. Il souligne.

${ }^{90}$ Voir Ibid., p. 62 et s. pour l'ensemble de sa démonstration.

${ }^{91}$ Chr. Lynch, O Momento Monarquiano, op. cit., pp. 256-257.

${ }^{92}$ Voir R. Spaemann, Un philosophe face à la Révolution. La pensée politique de Louis de Bonald, Paris, Hora Decima, 2008, p. 98 et s. Son programme est ainsi à l'opposé de celui de Constant : comme l'analyse St. Holmes, Benjamin Constant et la genèse du libéralisme moderne, Paris, P.U.F., 1994, pp. 180-183, le politique chez Constant n'a plus la même finalité téléologique que chez Aristote : il n'est « pas de son ressort d'exprimer l'essence de l'homme ou de faire respecter les normes d'une orthodoxie morale quelconque ». Ainsi rompt-il avec le concept polysémique de politeia, en interdisant expressément au pouvoir d'organiser le progrès ou le salut des âmes : l'Etat ne se confond plus avec les mœurs des citoyens. Sur ce thème, voir aussi E. Harpaz, «Benjamin Constant entre la République et la Monarchie », in Annales Benjamin Constant, n²12, 1991, p. 48 et s. et P. Manent, Les libéraux, Paris, Gallimard, 2001, pp. 29-33.

93 «Une société, pour être parfaitement constituée, devrait avoir toutes les lois nécessaires à sa conservation, et toutes naturelles. Là, il n'y aurait plus de lois à porter, et il suffirait de les maintenir par l'action continuelle de l'administration, contre l'action continuelle du temps et des hommes, qui tendent à les détruire. Ainsi, dans cette société, le pouvoir législatif devrait toujours être en repos, et les fonctions exécutives toujours en action ». Législation primitive, considérée dans les derniers temps par les seules lumières de la raison, tome II, in L. de Bonald, CEuvres complètes, Paris-Genève, Slatkine, 1982 (réimpression de l'édition Adrien Le Clere, 1817-1843), vol. III, pp. 37-38.
} 
Fonfrède ${ }^{94}$, se veut actif, soit en montrant l'exemple suivant la tradition du miroir des princes ${ }^{95}$, soit en réprimant les mauvais comportements à l'instar de la mission de pasteur. D'autre part, ce rôle s'évertue à contenir l'innovation en matière législative, rôle actif et passif légitimant la sanction royale ; dans la perspective ultraroyaliste, il s'agit d'entériner le but premier du Pouvoir, la Justice, autrement dit de rendre à chacun son dû, celui-ci étant prédéterminé par une loi fixe : la Coutume. En résumé, conserver signifie ici préserver les croyances et les mœurs de la société. Dans la perspective conservatrice, en revanche, le roi doit suivre l'évolution des mœurs et se contenter d'accompagner le mouvement, en censurant ce qui n'est pas juste (ce qui outrage la conservation et/ou le développement sain de la société), en consacrant ce qui l'est. Concrètement, il prévient le danger inhérent à l'innovation, car celle-ci porte en germe un esprit de destruction ${ }^{96}$. L'importance de ce dessein explique le caractère conséquent des prérogatives du Roi et implique sa mainmise sur les institutions. Précisément, c'est en prônant une hiérarchie qui consacrerait la suprématie du Roi que Fonfrède parviendrait à satisfaire pleinement Henriques de Souza :

«Tous les pouvoirs de l'Etat, en conservant chacun leur indépendance relativement à leurs fonctions légales et constitutionnelles, doivent être hiérarchiquement au-dessous de la royauté, tenant d'elle une partie de leur organisation, de leur vie réglementaire ; attachés, en un mot, à la royauté par un lien qui ne laisse dans la machine gouvernementale aucune lacune, aucune lézarde par où l'anarchie puisse s'introduire et disjoindre l'édifice social $»^{97}$.

Nous ne sommes pas surpris d'apprendre que l'ouvrage du professeur de Recife présentait une portée politique, lui qui visait les tenants brésiliens du parlementarisme ${ }^{98}$, en particulier Zacharias de Goes e Vasconcellos ${ }^{99}$. Dans un opuscule au nom trompeur paru en $1860^{100}$, celui-ci s'attachait en effet à employer un argumentaire usé (quis custodiet custodem ? ${ }^{101}$ ) afin de réduire à néant l'autonomie de l'Empereur en réclamant l'extension de la responsabilité ministérielle aux actes émanant de son pouvoir modérateur. Il s'agissait ainsi de lutter contre ce qu'il présentait, par goût de la provocation, comme un reliquat inconséquent et anachronique des arcana imperii ${ }^{102}$ :

«Affirmer qu'aucune personne ne surveille le pouvoir modérateur, que ses actes sont de véritables mystères - arcana imperii- fournit la preuve d'une vénération pour le pouvoir monarchique, mais d'une vénération excessive, propre aux seules monarchies absolues [...]. Dans un régime représentatif, il existe quelqu'un qui

\footnotetext{
${ }^{94}$ «Pour être le directeur moral de la société, pour exercer sur elle cette action que j’ai nommée le gouvernement des esprits, la royauté constitutionnelle a trois instruments gouvernementaux : les chambres, la presse, l'éducation ». De la société, du gouvernement et de l'administration, tome III, in Euvres complètes de Henri Fonfrède, Paris, Coquebert, 1844, tome III, p. 241. Il souligne.

${ }^{95}$ Voir par exemple Pr. de Barante, Des divers projets de constitution pour la France, Paris, Mame frères, 1814, pp. 5254. Sur les miroirs des princes et les ouvrages de morale et de «pédagogie royale», voir J. Krynen, L'empire du roi. Idées et croyances politiques en France XIIIe-XVe siècle, Paris, Gallimard, 1993, pp. 170-224 ; M. Sénellart, Les arts de gouverner. Du regimen médiéval au concept de gouvernement, Paris, éd. du Seuil, 1995, pp. 45-58 et passim.

${ }^{96}$ De la société, du gouvernement et de l'administration, t. I, in Euvres complètes de Henri Fonfrède, op. cit., t.I, p. 120

${ }^{97}$ Ibid., tome II, in Euvres complètes de Henri Fonfrède, op. cit., tome II, p. 321.

${ }^{98}$ Sur ce débat passionné sur le pouvoir modérateur des années 1860, en plus des ouvrages de Nogueira Saldanha et de Lynch, voir J. Murilo de Carvalho, Un théâtre d'ombres : la politique impériale au Brésil (1822-1889), Paris, éd. de la Maison des sciences de l'homme, 1990, traduction par Cécile Tricoire, p. 154 et s.

${ }^{99}$ Avocat de profession, ce politique libéral (1815-1877), cofondateur du Partido Liberal Progressista (qui sera dissout en 1868 par D. Pedro II), fut plusieurs fois ministre et Président du Conseil des ministres à trois reprises.

${ }^{100}$ Z. de Goes e Vasconcellos, Da natureza e limites do Poder Moderador, Rio de Janeiro, Typographia de Nicolau Lobo Vianna e filhos, 1860. Contrairement à ce qu'indique le titre (de la nature et des limites du pouvoir modérateur), l'auteur traite essentiellement de la responsabilité des ministres.

${ }^{101}$ Il s'agit évidemment d'une adaptation du célèbre quis custodiet ipsos custodes de Juvénal.

102 Sur les arcana imperii, voir M. Sénellart, Les arts de gouverner, op. cit., pp. 245-277. En tant que mystères ou secrets de l'Etat, englobant le recours à des machinations et à des pratiques compliquées et occultes, ces arcanes traduisaient souvent une conception mystique de la prérogative royale qu'il ne convenait pas de disputer suivant Jacques $I^{\text {er }}$ d'Angleterre. Par cette comparaison, le conseiller Zacharias souhaite donc discuter du fond de la théorie du pouvoir modérateur afin de dissiper les zones d'ombre soigneusement maintenues par les conservateurs.
} 
veille sur le pouvoir royal ou modérateur, comme il en existe qui veillent sur tous les autres pouvoirs : c'est l'opinion nationale, par l'intermédiaire des chambres et de la presse ${ }^{103}$.

A ce stade, ce sont les sources qu'il emploie qui nous importent. Or, celles-ci s'abreuvent nettement du côté de l'Angleterre, travestissant allègrement le texte constitutionnel originel. Le conseiller Zacharias interprète en effet la constitution brésilienne à la lumière de Blackstone, de Stephen et de Macaulay; la séparation entre pouvoir modérateur et pouvoir exécutif trouve ainsi une bien curieuse explication : il s'agirait ni plus ni moins que de l'application de la division du travail ${ }^{104} \ldots$ L'invocation des travaux des publicistes anglais poursuit essentiellement l'objectif d'introduire la maxime the king can do no wrong, qu'il répète inlassablement. Quant aux sources françaises, s'il est parfois fait mention de Guizot, Foucart, Dupin ou encore Foy, leur usage, le plus souvent décoratif, ne fait nullement référence à la théorie du pouvoir modérateur. La seule exception notable provient des citations empruntées aux ouvrages de Benjamin Constant ; mais, ici encore, Constant est étrangement interprété, et parfois fustigé, à la lumière des auteurs du pays d'Albion qui, selon le politique brésilien, constitueraient les sources uniques ayant servi de guide aux conceptions du libéral de Coppet ${ }^{105}$. Les emprunts effectués par la constitution du Brésil aux «formulations ambiguës» de Constant sont en conséquence critiqués, le conseiller Zacharias n'hésitant pas à proposer une relecture du sujet et des écrits du parlementaire français à travers le prisme de Stephen, dont les théories s'avéreraient bien plus claires ${ }^{106}$. Ces supposées reprises ne convainquaient d'ailleurs personne, tant les erreurs de (l'éventuelle) retranscription se révèlent notables, voire comiques. Les commentateurs ${ }^{107}$ s'amusent en effet à relever l'erreur existant entre ce passage récurrent des écrits de Constant («On s’étonnera de ce que je distingue le pouvoir royal du pouvoir exécutif. Cette distinction toujours méconnue est peut-être la clé de toute organisation politique ${ }^{108}$ ) et la formulation de l'article 98 qui applique l'expression «clé de toute organisation politique » (《chave de toda a organização politica ») non plus à la distinction entre pouvoir royal et pouvoir exécutif, mais à l'existence même du pouvoir modérateur, ce qui en modifie radicalement le sens et la portée ${ }^{109}$.

Aucun effort n'est donc consenti pour tâcher de comprendre le sens et la nature du pouvoir modérateur ; Constant est régulièrement tourné en dérision, jugé dans tous les cas inférieur en clarté aux théories « originairement » puisées en Angleterre, qu'il convient par conséquent de reprendre à la source. Du point de vue des libéraux progressistes, à l'instar de Tobias Barreto qui consacra également un opuscule à ce sujet ${ }^{110}$, la question du pouvoir modérateur semble anachronique et les sources françaises occultées ou réduites au maximum; l'unique exception concerne Benjamin Constant, ce qui n'empêche nullement les virulentes offensives portées à l'encontre de ses idées. Seuls les membres ou les sympathisants du Partido Conservador, certes dominant, osent encore

\footnotetext{
${ }^{103}$ Z. de Goes e Vasconcellos, Da natureza e limites do Poder Moderador, op. cit., p. 26.

${ }^{104}$ Z. de Goes e Vasconcellos, Ibid., pp. 14-16.

105 Voir notamment Ibid., p. 28 et s. Affirmation fausse comme nous l'avons vu. Dans une note à ses Réflexions sur les constitutions, Constant reconnaîtra même que le modèle anglais, en raison de certaines prérogatives remis au roi susceptibles d'altérer sa neutralité, ne peut « servir de règle aux peuples appelés à jouir du bienfait de la liberté sous la monarchie »; les références qu'il maintient à son sujet, certes omniprésentes, ne servent qu'à illustrer de façon aisée ses idées, mais le modèle anglais n'en est pas un. Il le répétera : l'Angleterre a un pouvoir neutre de fait, non de droit.

106 Z. de Goes e Vasconcellos, Da natureza e limites do Poder Moderador, op. cit., pp. 4-5.

107 Voir le résumé qu'en livre N. Nogueira Saldanha, Historia das Idéias Politicas no Brasil, op. cit., p. 124.

108 Article « Observations sur la Charte portugaise » du 27 juillet 1826, in B. Constant, Recueil d'articles 1825-1829, Paris, Librairie Honoré Champion, 1992, p. 69.

${ }^{109}$ L'expression ressemble plus, dans son esprit, à celle proposée par Destutt de Tracy dans son Commentaire sur l'esprit des lois de Montesquieu, Genève, Slatkine reprints, 1970 (réimpression de l'éd. de Paris, 1819), pp. 206-207 : «Je me suis un peu étendu sur ce qui regarde ce corps conservateur, parce que cette institution a été imaginée depuis peu, et parce qu'elle me paraît de la plus extrême importance. C'est, suivant moi, la clef de la voûte, sans laquelle l'édifice n'a aucune solidité et ne peut subsister ».

110 Jugé superficiel et surtout partial, en raison de sa haine envers D. Pedro II, par J. de Scantimburgo, O poder moderador, op. cit., pp. 30-31.
} 
s'appuyer sur la diversité du libéralisme français, Lanjuinais en tête ${ }^{111}$; mais ce parti, crée en 1837 , étant issu de l'alliance entre regressistas et libéraux modérés ${ }^{112}$, contribue par sa diversité intrinsèque à multiplier les confusions quant à la nature et quant aux sources du pouvoir modérateur comme en atteste l'ouvrage du professeur de Recife. A moins qu'il ne s'agisse précisément d'un aveu quant à la véritable signification d'une idée en vérité partiellement libérale...

En tout état de cause, ces éléments se révèlent précieux pour notre enquête. D’une part, ils nous renseignent sur l'animadversion portée à l'encontre des publicistes étrangers au Brésil. Abordant le cas de Lanjuinais, Henriques de Souza déplorait cet état d'esprit en prenant appui sur une confession livrée par le conseiller Zacharias lors d'une session parlementaire :

«Lors du discours prononcé le 16 juillet 1864 pendant la session de la chambre temporaire, M. le Conseiller Zacharias stigmatisa la haine qui transpirait, dans la tenue du débat, à l'encontre des publicistes étrangers qui furent cités afin d'éclairer la question qui nous occupe. [...] La haine des autorités scientifiques ne peut être que le fruit d'une vanité présumée emplie d'ignorance : ceux qui récusent l'aide nécessaire à la bonne compréhension des lois, puisée dans les sources des législateurs, le font afin de substituer leur propre volonté (digne à ce titre de mépris) à la volonté du pouvoir public déclarée solennellement. Nous espérons par conséquent que M. le Conseiller ne récusera pas l'emprunt que nous avons effectué en amont à l'illustre comte de Lanjuinais $»^{113}$.

D'autre part, ils expliquent le tarissement des sources, limitées de plus en plus au seul Constant. Or, celui-ci tend progressivement à ne plus être étudié dans le corps du texte, ce qui, paradoxalement, n'interdit pas de méditer «ses» idées ${ }^{114}$. Donnée étonnante, la paternité du pouvoir modérateur attribuée à Constant bénéficie non pas du patronage d'une autorité brésilienne ou de recherches sur le sujet, mais bien de l'invocation presque systématique ${ }^{115}$ de ce passage de l'Histoire de la civilisation européenne de F. Guizot, devenu, par le fruit savoureux des circonstances, l'apôtre de Constant au Brésil :

« Ouvrez l'ouvrage où M. Benjamin Constant a si ingénieusement représenté la royauté comme un pouvoir neutre, un pouvoir modérateur, élevé au-dessus des accidents, des luttes de la société, et n'intervenant que dans les grandes crises. N'est-ce pas là [...] l'attitude du souverain de droit dans le gouvernement des choses humaines ? Il faut qu'il y ait dans cette idée quelque chose de très propre à frapper les esprits, car elle a passé avec une rapidité singulière des livres dans les faits. Un souverain en a fait, dans la constitution du Brésil, la base même de son trône. La royauté y est représentée comme pouvoir modérateur, élevé au-dessus des pouvoirs actifs, comme spectateur et juge $»^{116}$.

\footnotetext{
${ }^{111}$ N. Nogueira Saldanha atteste qu'il s'agit d'un auteur commun à la culture brésilienne dans son Historia das Idéias Politicas no Brasil, op. cit., p. 131. Mais, en présentant dans la même page Ch.-G. Hello comme un ultraroyaliste (!), nous aurions tôt fait de nous interroger sur les connaissances brésiliennes de ces auteurs, en dehors précisément des milieux conservateurs du XIX $\mathrm{X}^{\mathrm{e}}$ siècle qui nous ont paru être les seuls à maittriser la culture politique française.

112 Voir A. Enders, Nouvelle histoire du Brésil, Paris, Chandeigne, 2008, pp. 132-134. Le programme des deux partis est bien présenté dans Oliveira Lima, O Império Brasileiro 1822-1889, São Paulo, Melhoramentos, 1927, p. 40 et s.

${ }^{113} \mathrm{Br}$. Fl. Henriques de Souza, $O$ poder moderador, op. cit., p. 348 en notes.

${ }^{114} \mathrm{~L}$ 'exemple le plus intrigant provient de l'étude de l'académicien brésilien J. de Scantimburgo qui prend rapidement une tournure politique : sans se soucier du respect de la théorie de Constant, Scantimburgo l'utilise afin de démontrer le caractère essentiel d'un pouvoir typiquement conservateur au Brésil. Le pouvoir modérateur devient ainsi un arbitre entre les partis, chargé de «conserver la société » en représentant seul la «volonté suprême de la société », unifiant ainsi les différentes forces sociales. L'assemblée, en revanche, ne doit représenter que des intérêts. Voir J. de Scantimburgo, O poder moderador, op. cit., pp. 9, 33, 141, 241-251 et passim. Son approche partisane s'inspire bien plus des thèses d'Henri Fonfrède qu'il ne connaît pourtant pas, si ce n'est à travers l'œuvre de Henriques de Souza, qui lui sert en partie de guide dans sa lutte contre la pensée politique moderne.

${ }^{115}$ Comme l'atteste, sans en mesurer la portée, N. Nogueira Saldanha, Historia das Idéias Politicas no Brasil, op. cit., p. 125.

${ }^{116}$ Fr. Guizot, Histoire générale de la civilisation en Europe, depuis la chute de l'empire romain jusqu'à la Révolution française, Bruxelles, société belge de librairie Hauman et Cie, 1844, p. 221 (9 ${ }^{\text {ème }}$ leçon).
} 
Cet extrait des œuvres de Guizot devait à son tour marquer les auteurs portugais, accréditant chaque jour un peu plus la thèse de la paternité de Constant, sans égard au fond des théories ${ }^{117}$. L'illustre libéral et poète romantique, Alexandre Herculano, se présente ici comme un exemple intéressant, lui qui ne cite jamais Constant à sa source, mais qui ne peut s'empêcher de lui attribuer la paternité du pouvoir modérateur de la charte constitutionnelle portugaise de 1826 en reproduisant le fameux passage de Guizot ${ }^{118} \ldots$ En dépit d'une plus grande proximité des frontières, les Portugais se seraient-ils à leur tour égarés, en occultant la diversité des sources ayant contribué à la naissance de leur pouvoir modérateur?

\section{II- L'approche portugaise du pouvoir modérateur : la tentation avortée d'une voie originale}

«Je m'étonne que l'illustre député [référence à son préopinant] soit remonté si loin et ait trouvé les sources de notre Charte constitutionnelle chez un écrivain, [...] Benjamin Constant. Quant bien même nous retrouverions des dispositions identiques aux doctrines d'un auteur, nous ne pouvons affirmer que ses sources sont l'œuvre de ce dernier, et que l'on doit interpréter la Charte à la lumière de ses théories ${ }^{119}$. S'il s'oppose ouvertement à la parenté intellectuelle de Constant, le député Simas ne dépareillait pourtant pas significativement de l'ensemble des parlementaires portugais ; ceux-ci se disputaient régulièrement quant à la place à accorder aux autorités intellectuelles françaises. En effet, à l'exception des afrancesados, les Portugais entretinrent pendant longtemps une relation ambiguë avec les écrits provenant de la France ${ }^{120}$. A la différence du Brésil francophile, le libéralisme au Portugal s'est originellement nourri d'un profond ressentiment envers la France et les «idées nouvelles $»^{121}$, comme en atteste le nombre conséquent de pamphlets entre 1807 et $1814^{122}$. Cette légende noire de la Révolution française, bien entretenue, va profondément marquer les esprits : en suscitant un certain attachement envers les institutions d'Ancien Régime, elle alimentera le courant contre-révolutionnaire, récupéré plus tard par D. Miguel ; en discréditant les doctrinaires français, elle persuadera les premiers libéraux portugais de suivre la voie du constitutionnalisme modéré, puisé de préférence en Angleterre ${ }^{123}$. Cette méfiance doit certes être tempérée, la précédente constitution portugaise, celle de 1822, s'inspirant sans conteste de la Constitution française de 1791 ; mais il convient de le souligner : si ce modèle est manifeste, il est surtout tacite à travers l'omniprésente et bien moins embarrassante invocation de la

\footnotetext{
${ }^{117}$ Ils ont également pu être égarés par cette affirmation erronée de Pinheiro Ferreira, alors réfugié en France : « Nous avons déjà fait observer que la plupart des publicistes ne font mention que des pouvoirs législatif, exécutif et judiciaire ; [...] quant au pouvoir conservateur, si on excepte le premier aperçu que M. Benjamin Constant en a donné sous le nom de pouvoir modérateur, nous ne connaissons aucun autre publiciste qui y ait prêté l'attention que l'objet nous semble mériter [...] ». S. Pinheiro Ferreira, Cours de droit public interne et externe, Paris, Rey et Gravier, 1830, t. II, p. 376.

118 Voir J. Barradas de Carvalho, As ideias politicas e sociais de Alexandre Herculano, Lisbonne, Tip. Gracia e Carvalho, 1949, p. 122. Cette invocation de Guizot en appui à la thèse de la paternité de Constant se retrouve naturellement lors des débats parlementaires : cf. par exemple l'intervention de Carlos Bento, 20 mars 1874, in Diario da Câmara dos Senhores Deputados da Nação Portugueza, legislatura 20, sessão 4, n 52 , p. 821.

${ }_{119}$ Intervention du député Simas, 26 mars 1846, in Diario da Câmara dos Senhores Deputados da Nação Portugueza, legislatura 6, sessão $1, \mathrm{n}^{\circ} 20$, p. 17.

${ }^{120}$ L'histoire est bien retranscrite par L. A. de Oliveira Ramos, « Le Portugal et la Révolution française (1777-1834) », in Les révolutions dans le monde ibérique (1766-1834), tome I : la péninsule, P. U. de Bordeaux, 1989, pp. 183-234.

${ }^{121}$ Contrairement au Brésil, les Francs-maçons portugais n'ont guère œuvré en faveur de leur diffusion, se bornant à transmettre la structure et les rites de la franc-maçonnerie. Voir Gr. et J. Sebastião da Silva Dias, Os Primordios da Maçonaria em Portugal, Lisbonne, Instituto Nacional de Investigação Cientifica, 1980, vol. I, t. II, p. 510.

122 Voir A. Pedro Vicente, «Le Portugal devant la révolution française - attitudes contradictoires», in La Révolution française vue par les Portugais, actes du colloque de Paris, 17-18 novembre 1989, Fondation Calouste Gulbenkian, Centre culturel portugais, Paris, 1990, pp. 95-96.

${ }^{123}$ Ibid., pp. 97-99. Au contraire, le Brésil encore colonisé, mais soucieux de conquérir son indépendance, devait puiser ses sources dans celles rejetées par le libéralisme portugais. Comble de cette défiance, entre 1817 et 1822, l'opinion publique brésilienne préférait être gouvernée par un monarque absolu, si le Roi restait de leur côté de l'Atlantique, que par les cortes portugaises converties au libéralisme. L'animosité conduisait ainsi au rejet du « libéralisme officiel » de la métropole. Voir N. Nogueira Saldanha, Historia das Idéias Politicas no Brasil, op. cit., p. 87.
} 
Constitution de Cadix ${ }^{124}$. Notons enfin que les Cortes, comme le prouve leur correspondance, avaient alors recherché et obtenu le patronage de Bentham ${ }^{125}$, afin de se démarquer encore un peu plus des théories françaises; celles-ci se révèlent pourtant décelables à travers l'invocation d'auteurs, perçus comme modérés, sous la Restauration.

L'octroi en 1826 d'une charte inspirée par celle du Brésil indépendant ${ }^{126}$, elle-même puisée dans la doctrine d'auteurs français, devait naturellement indisposer certains parlementaires; il est d'ailleurs possible de rencontrer des débats houleux sur la question de la paternité, comme lors du 17 avril 1848 où non seulement la paternité de Constant est contestée avec une rare violence, mais également l'idée que la Charte serait un calque de la constitution honnie provenant du Brésil ${ }^{127} \ldots$ L'histoire constitutionnelle mouvementée du Portugal, entre dictature, rétablissement de l'absolutisme et menées révolutionnaires, explique le destin chaotique de la charte ${ }^{128}$, propice à ces entreprises de contre information, et le nombre restreint de débats parlementaires sur le pouvoir modérateur avant 1842. En dépit d'une conjoncture comparable, par sa difficulté, à celle du Brésil, le pouvoir modérateur du Portugal ne devait pas subir autant l'interférence française, sauf à invoquer tardivement l'autorité de Constant afin d'introduire le parlementarisme anglais. L'ont-ils trahi ? En apparence, les Portugais se détournent surtout des conservateurs français comme Fonfrède, totalement absent des discussions ${ }^{129}$, pour embrasser la cause du «Roi règne et ne gouverne pas »; leur approche du pouvoir modérateur devait en conséquence le réduire, suivant l'expression du ministre de la justice Silva Cabral ${ }^{130}$, à une fonction «d'inspection ou de superintendance constitutionnelle ${ }^{131}(\mathrm{~B})$, qui respecte la tradition libérale triomphante d'un Lanjuinais, seul père revendiqué lors de la période 1826-1828, mais rapidement oublié (A).

${ }^{124}$ Voir R. Garnier, Un modèle européen de démocratie : le cas portugais, Paris, L.G.D.J., 2005, pp. 31 et $37-42$.

${ }^{125}$ M. H. Carvalho dos Santos, ««A maior felicidade do maior numero». Bentham e a Constituição Portuguesa de $1822 »$, in O liberalismo na Peninsula Ibérica na primeira metade do século XIX, Lisbonne, Sa da Costa, 1982, t. I, p. 91 et s.

${ }^{126}$ Une tradition populaire attribue la rédaction de la charte de 1826 à José Joaquim Carneiro de Campos, l'écrivain de la Constitution de 1824. Il semble néanmoins que le processus rédactionnel fut plus curieux, fruit d'un échange de réflexions et d'annotations sur la base de la constitution brésilienne entre D. Pedro et Gomes da Silva, son secrétaire au sein du Cabinet. L'empressement et la lassitude aidant, il semble que D. Pedro n'ait pas accordé un grand soin à son travail. On peut retrouver une description détaillée de cette élaboration au sein de l'introduction de l'ouvrage d'A. Arinos, O constitucionalismo de D. Pedro I no Brasil e em Portugal, édition du Ministère de la Justice du Brésil, 1972.

${ }^{127}$ Voir la réponse motivée, proche d'une glose de la Charte, du député Avila face à cette double attaque, dans Diario da Câmara dos Senhores Deputados da Nação Portugueza, legislatura 7, sessão 1, n¹3, 17 avril 1848, pp. 6-7.

${ }^{128}$ On distingue trois périodes de vigueur du texte. La première fut brève, entre le 29 avril 1826 et le 11 juillet 1828 , date à laquelle D. Miguel devint roi et réussit à obtenir l'annulation (et non simplement l'abrogation) par des Cortes des actes pris par D. Pedro à la mort de leur père en se fondant sur le défaut de compétence de son frère. La deuxième le fut tout autant : la charte fut remise en vigueur le 23 mai 1834 suite à la victoire du parti libéral sur les « miguelistas » à la fin de la guerre civile qui entraîna la signature de la «Concessão de Evora-Monte » et scella le sort de D. Miguel, une nouvelle fois contraint à l'exil. La charte ne demeurera toutefois effective que jusqu'à la révolution du 10 septembre 1836. La troisième et dernière fut plus fructueuse, débutant avec le coup d'Etat de Costa Cabral en janvier 1842 (charte officiellement rétablie le 11 février 1842) avant de céder face aux coups de butoir de la République le 5 octobre 1910.

${ }^{129}$ Ce dédain peut s'expliquer par ce jugement déplacé de Fonfrède sur le Portugal. Conformément à la théorie des climats de Montesquieu mais aussi à la perfectibilité de l'espèce humaine d'un Condorcet, il estimait que les mœurs de la population portugaise, entre autres éléments propres au pays, n'étaient pas prêtes à accueillir un autre régime qu'une monarchie absolue, sous peine de déboucher sur un conflit : «En effet, comme en Espagne et en Portugal il n'y avait réellement ni mœurs, ni majorité dans le sens de la monarchie constitutionnelle ; comme les anciennes mœurs et les anciens intérêts du pays avaient pris racine, et s'étaient depuis longtemps établis sur des bases contraires, il en est résulté, - et cela ne pouvait être autrement, - que l'établissement de la monarchie constitutionnelle devait être le signal d'une violente lutte, et la cause d'une transition pénible et sanglante [...] ». De la société, du gouvernement et de l'administration, tome III, in Euvres de Henri Fonfrède, op. cit., tome III, p. 132.

${ }^{130}$ Avec ses deux frères, dont Costa Cabral, homme fort du pays entre 1842 et 1846, José da Silva Cabral aura la mainmise sur les institutions. Cette association des trois frères, surnommés les « cabralistas », portera ses fruits d'un point de vue économique; d'un point de vue politique en revanche, ils devaient subir les critiques virulentes d'une alliance pour le moins bigarrée couvrant un spectre allant du centre gauche à l'extrême droite migueliste.

${ }^{131}$ Silva Cabral («inspecção ou superintendência constitucional »), in Diario da Câmara dos Senhores Deputados da Nação Portugueza, legislatura 5, sessão 3, n58, 30 octobre 1844, p. 335. 


\section{A- Le pouvoir modérateur et ses sources françaises : histoire d'un oubli}

Jusqu'à la fin des années 1840, Benjamin Constant semble surtout être invoqué en qualité d'autorité tutélaire et emblématique du libéralisme et du constitutionnalisme moderne. Tel était déjà l'emploi qui en était fait par les libéraux vintistas lors du règne de la constitution libérale portugaise de 1822 : cité à douze reprises dans le Diario das Cortes geraes e extraordinarias da Nação portugueza, la référence à Constant ne sert qu'à appuyer des principes libéraux classiques tels que la responsabilité ministérielle ${ }^{132}$ ou le pouvoir du Roi de signer des traités, sous réserve du contrôle ultérieur du Parlement ${ }^{133}$. Pour des raisons évidentes, dues à l'absence de pouvoir modérateur dans la constitution portugaise de 1822, presque aucune référence n'est alors faite au pouvoir neutre ${ }^{134}$. Mieux, même si Benjamin Constant paraît être le libéral français le plus mentionné, il n'éclipse pas totalement les autres : Royer-Collard, Foy, Hello, Pagès, Germaine de Staël ou encore Camille Jordan (orthographié Camillo Jourdan) sont cités au moins une fois. Quant à Lanjuinais, il est placé à égalité, avec Constant, parmi les pères du libéralisme par rien de moins que Pereira de Carmo ${ }^{135}$, l'une des principales figures du mouvement vintista, également connu pour avoir rédigé le testament de Dom Pedro IV, le futur auteur de la Charte, dont il était proche.

S'il est difficile de déterminer les sources d'une charte octroyée, il semble déjà acquis que la connaissance portugaise de la pensée libérale française ne se limitait nullement à Benjamin Constant. D'ailleurs, si ce dernier faisait l'objet de traductions en portugais, il en allait de même pour Lanjuinais ; celui-ci a même rédigé un ouvrage spécialement dédié aux Siciliens et, de façon peut-être moins connue, aux Portugais, destiné à influencer leur travail de rédaction constitutionnelle ${ }^{136}$. Si elle rechigne souvent à l'admettre pour des raisons historiques, la culture libérale portugaise est pour le moins imprégnée du pluralisme, comme des subtilités, du libéralisme français classique, du moins jusqu'en 1840. A partir de cette date, si les références sont encore saillantes à propos des politiques français au pouvoir, Thiers et Guizot en tête, la variété de ce premier libéralisme tend à se tarir au sein des esprits des députés portugais, qui n'en retiennent finalement que la figure principale : Benjamin Constant. Il apparaît en effet à plus de quatre-vingt reprises sous le règne de la Charte de 1826, là où ses frères d'armes tendent à disparaître : par exemple, si Lanjuinais le concurrence de loin jusqu'en 1840, son nom ne sera plus jamais prononcé avant 1902. Tout le contraire de Constant qui tend, sur cette même période, à asseoir sa notoriété posthume de père du libéralisme...et de père du pouvoir modérateur de la Charte. A l'instar de Carlos Bento en 1874 ou d'Avila en 1848, nombreux sont ceux qui défendent alors cette thèse, sans saisir les nuances à apporter à leur analyse ; faute de connaissances, leurs contradicteurs, comme Simas, Thomas Ribeiro ou encore Laranjo, se contentent souvent de recycler un argument caricatural, partagé depuis par certains positivistes, savoir que Benjamin Constant n'est plus qu'un

\footnotetext{
${ }^{132}$ Diario das Cortes geraes e Extraordinarias da Nação Portugueza, legislatura 1, sessão 1, n²50, 14 décembre 1821 , p. 3408. Intervention de Annes de Carvalho.

${ }^{133}$ Ibid., legislatura 1, sessão 1, n²37, 28 novembre 1821, p. 3251. Intervention de Pinto de Magalhães.

${ }^{134} \mathrm{La}$ seule exception notable provient du député Bastos qui, en prônant l'existence d'un «cinquième pouvoir», paraphrasa la théorie du pouvoir neutre ; la proposition fut immédiatement rejetée, la thèse de Constant étant jugée « non pertinente ». Ibid., legislatura 1, sessão 1, n 156, 20 août 1821, pp. 1948-1949.

${ }^{135}$ Ibid., legislatura 1, sessão $1, \mathrm{n}^{\circ} 21$, session du 21 février 1821, p. 140. Bento Pereira de Carmo, né le 29 mars 1776 , a fait des études de droit avant de devenir juge. Libéral de la première heure, il fut membre du gouvernement par intérim faisant suite au pronunciamento du 15 septembre 1820 puis élu député jusqu'à la contre-révolution. Partisan de D. Pedro, il sera harcelé en tant que libéral et placé sur la liste des suspects, c'est-à-dire les personnes cherchant à attenter à la sûreté de l'Etat (comprendre en sa forme absolutiste), et sera même emprisonné puis jugé pour son appartenance à la Franc-maçonnerie. Elu premier président de la Relação le 30 juillet 1833 après la défaite de D. Miguel, il poursuivra sa carrière politique en tant que ministre du 23 avril 1834 jusqu'au 24 septembre de la même année.

136 Il s'agit de ses Vues politiques sur les changements à faire à la Constitution d'Espagne, afin de la consolider, spécialement dans le royaume des Deux-Siciles, paru en 1821, et qui a bénéficié d'une traduction immédiate sous le titre Considerações politicas sobre as mudanças que conviria fazer na constituição hespanhola, a fim de a consolidar em o reino das duas Sicilias, Lisbonne, Typ. Rollandia, 1821. Même si son titre ne l'indique pas, Lanjuinais s'adresse également, tout au long de ce livre, aux Portugais.
} 
«publiciste fossile $»^{137}$ et « décrépit ${ }^{138}$ sans importance pour le présent... Autrement dit, la réfutation ne porte pas sur la paternité de l'idée, sujet insignifiant voire embarrassant qu'ils préfèrent esquiver, mais sur sa pérennité et son actualité, prétextant d'une modification des mœurs et des avancées de la « science » juridique et constitutionnelle.

Cette méconnaissance se perpétue depuis dans les ouvrages contemporains qui, à force de reprendre des sources de seconde main, obscurcissent toujours plus la vérité, multipliant malencontreusement les erreurs en cédant à des raccourcis discutables ${ }^{139}$.

La réponse à notre question initiale ne peut donc se trouver qu'en amont, plus exactement vers la fin des années 1820 faisant suite à l'octroi. Le silence sur la paternité de Constant lors de cette période risque peut-être d'étonner. Mais que dire alors de la paternité affirmée de Lanjuinais par le député Alexandre Thomaz de Moraes Sarmento ${ }^{140}$ en 1827, lui qui est un proche du pouvoir et sera un fidèle soutien de la reine Dona Maria II ? Assurément, voilà un témoignage précieux jetant le trouble quant à la paternité de l'idée du pouvoir modérateur portugais et brésilien :

«Il fut déjà démontré, en d'autres occasions, que les salaires limiteraient nécessairement le nombre de conseillers d'Etat, et, qu'en le limitant, nous irions restreindre l'Autorité Royale ; en effet, le Conseil d'Etat est un Appendice du Pouvoir Exécutif, ou plutôt du Pouvoir Modérateur, selon la classification entérinée par notre Charte, qui a consacré, en guise de doctrine politique, les enseignements que le comte de Lanjuinais avait suggérés dans ses Doctrines théoriques sur l'organisation des pouvoirs constitutionnels ${ }^{141}$.

Pour exceptionnelle qu'elle soit, compte tenu de la rareté des débats sur la question sur la première période de vie de la Charte, cette intervention reflète pourtant une vérité souvent tue : pour la plupart des parlementaires portugais du règne de D. Maria II (1826-1828 et 1833-1853), l'idée du pouvoir modérateur est à mettre au compte non pas d'un publiciste, mais des publicistes modernes. Ses défenseurs, en ne retenant que la France et le Portugal, sont en effet nombreux, quand bien même ceux-ci seraient aujourd'hui presque oubliés. Les références au seul Constant sont introuvables avant la fin des années 1840 ; elles deviennent exclusives après. Et s'il est effectivement mentionné lors de la période antérieure, il ne sert alors qu'à illustrer un point de la théorie, lui qui constitue l'autorité la plus aisée à citer compte tenu de la traduction de ses ouvrages, à une époque où l'apprentissage du français semble reculer dans les milieux éclairés. Ces invocations récurrentes permettent en outre d'écarter la thèse défendue par François Chevalier et Jean Chazelas : au Brésil, comme au Portugal, la référence aux «publicistes étrangers » ne vise nullement à voiler la paternité de Constant ${ }^{142}$; elle repose bel et bien sur une réalité, le pluralisme des sources, que les Français eux-mêmes tendent aujourd'hui à oublier. Il est enfin remarquable de constater que cette référence à la paternité de Lanjuinais représente un cas unique sur la première période du règne de la Charte (1826-1828), aucun autre "père » du pouvoir modérateur n'étant alors clairement mentionné. Quant à la seconde période d'activité de cette constitution (18341836), elle n'offre aucun élément de réponse, le débat se recentrant sur les contours du pouvoir modérateur. En résumé, avant la troisième et dernière application de la Charte, qui débute en 1842, soit à une période déjà bien éloignée des origines, Constant n'apparaît jamais en qualité de père du

\footnotetext{
${ }^{137}$ Nous préférons renvoyer à la réponse que livre Fontes Pereira de Mello, alors chef de l'opposition, contre cette «argumentation» dans Diario da Câmara dos Senhores Deputados da Nação Portugueza, legislatura 12, sessão 2, $\mathrm{n}^{\circ} 36$, p. 472 (session du 19 février 1861).

${ }^{138}$ Voir l'intervention de Thomas Ribeiro, séance du 10 avril 1880, in Ibid., legislatura 23, sessão 1, n68, p. 1370.

139 Pour prendre un exemple, J. Mattoso, dans son Historia de Portugal : O liberalismo (1807-1890), Editorial Estampa, 1993, p. 217, présente le pouvoir modérateur comme l'invention de Benjamin Constant, directement adopté de Clermont-Tonnerre.

${ }^{140}$ Moraes Sarmento (1786-1840), vicomte do Banho et frère aîné du baron de Moncorvo, fut député aux Cortes de 1820, 1822 et 1826. Membre du Supremo Tribunal de Justiça, la reine D. Maria II le nomma à la pairie en 1834. La même année, il fut envoyé à Madrid en qualité de ministre plénipotentiaire.

${ }^{141}$ Moraes Sarmento, intervention du 5 janvier 1827, in Diario da Câmara dos Senhores Deputados da Nação Portugueza, legislatura 1, sessão 1, n³, p. 30.

${ }^{142}$ Fr. Chevalier/J. Chazelas, « Le Brésil différent : un héritage original de la Révolution française », art. cité.
} 
pouvoir modérateur, sauf à le considérer comme faisant partie des «publicistes modernes » qui travaillèrent dessus.

Ce morcellement des sources permet donc de douter de l'application réelle et entière de la thèse défendue par le libéral de Coppet; il explique en partie les incompréhensions opérées par le texte portugais, relayées depuis par ses commentateurs. Paradoxalement, son invocation, à partir des années 1840, souvent très respectueuse de la leçon du maître, va servir à introduire puis à consolider le régime parlementaire, en reléguant de plus en plus le Roi dans une fonction de «superintendance constitutionnelle », sans emprise sur l'Exécutif; elle visait également l'objectif inverse, en interdisant au ministère d'accaparer, en pratique, les prérogatives que la Charte réservait expressément au pouvoir modérateur. Lors de l'important débat de février 1861, le député Ferrer devait ainsi chercher à rétablir la vérité constitutionnelle. Repoussant les comparatifs hasardeux avec l'Angleterre, non sans subir une interpellation à ce sujet, il prônait une séparation désormais consommée entre le pouvoir modérateur du roi et le pouvoir exécutif des ministres :

«Dans des pays comme l'Angleterre, la France et la Prusse, par exemple, où il n'existe pas de pouvoir modérateur, le pouvoir exécutif se charge de tous les actes, eux qui sont tous expédiés par les ministres...

Une voix : - Dans ces nations, il y a un pouvoir modérateur.

Ferrer : - Il y a un pouvoir modérateur jumelé avec le pouvoir exécutif. Mais il n'y a pas de pouvoir modérateur séparé du pouvoir exécutif. Cette séparation fut imaginée par un philosophe allemand avant d'être développée par Benjamin Constant, puis adoptée par la charte du Brésil et par la nôtre ${ }^{143}$.

Dans le prolongement de cette défense sur laquelle plane l'ombre de Constant, nombre de députés soulignent la nécessité de distinguer une différence d'essence entre les pouvoirs exécutif et modérateur. Devant la faiblesse désormais consommée du pouvoir royal face au pouvoir ministériel longtemps incarné par Saldanha ${ }^{144}$, l'intervention de Thomas de Carvalho vise ainsi à réserver au roi une sphère autonome de compétence, inaccessible au ministère en dépit de la mise en œuvre de leur responsabilité :

«J'eus l'occasion d'entendre un illustre député démontrer en ce lieu que le pouvoir modérateur était identique au pouvoir exécutif, citant plusieurs cas destinés à prouver l'absence de différence. En l'espèce, cette démonstration confond la forme et l'essence [de ces pouvoirs] : elle confond les aspects intérieurs avec les émanations perceptibles à l'extérieur ${ }^{145}$.

Il convient dès lors de s'interroger sur les raisons incitant l'opposition parlementaire à récupérer l'œuvre de Constant, désormais bien comprise. Car, en ne cédant jamais à la tentation du pouvoir conservateur, tout en cherchant à extraire le pouvoir modérateur du pouvoir exécutif, ces députés s'efforcent certes de lutter en faveur du régime parlementaire, mais aussi de brimer les tentations absolutistes d'un ministère en position de force. Le rehaussement de la fonction de « superintendance constitutionnelle » offrait à Constant une exclusivité au service d'une cause bien plus politique qu'institutionnelle. Mais, compte tenu de la conjoncture marquée par la véhémence d'une lutte continuelle, cette entreprise pouvait-elle réussir?

\footnotetext{
${ }^{143}$ Intervention du député Ferrer, 16 février 1861, in Diario da Câmara dos Senhores Deputados da Nação Portugueza, legislatura 12 , sessão $2, n^{\circ} 34$, p. 440.

${ }^{144}$ Comme l'expose R. Garnier, Un modèle européen de démocratie : le cas portugais, op. cit., p. 17 : « Le déclin du pouvoir royal va peu à peu donner naissance au pouvoir ministériel incarné par João Carlos de Saldanha en 1856 ». Soulignons toutefois que ce maréchal (1790-1876), petit-fils du marquis de Pombal, avait déjà exercé le pouvoir à différentes reprises lors des moments clefs du régime (1835-1836 ; 1846-1849; 1851-1856).

${ }^{145}$ Intervention du député Thomas de Carvalho, 20 février 1861, in Diario da Câmara dos Senhores Deputados da Nação Portugueza, legislatura 12, sessão 2, n³7, p. 484.
} 


\section{B- Le « superintendant constitutionnel » face au conservateur de la paix sociale}

«Nous ne pouvons argumenter à partir de la législation française, elle qui n'a pas constitué de Pouvoir Modérateur, ce d'autant plus que notre Conseil d'Etat, en plus de ne pas provenir de la Charte française, émane du Pouvoir Exécutif ; en conséquence, notre cas nous est strictement propre ${ }^{146}$. En soulignant l'échec de l'influence des idées françaises sur son propre droit, Silva Cabral veillait surtout à écarter les deux afin de proposer à ses concitoyens une voie propre au Portugal, renouant en partie avec le traditionalisme historique si cher aux libéraux vintistas ${ }^{147}$. Ses contemporains, du moins ceux placés à gauche ou au centre de l'Assemblée, cherchaient régulièrement à défendre leur vision du pouvoir modérateur, quitte à se démarquer d'influences théoriques un peu trop appuyées ${ }^{148}$; ils veillaient à ce titre à perpétuer les comparatifs, sans doute hasardeux, entre le pouvoir modérateur et le pouvoir royal de «l'Ancien Régime » portugais $^{149}$. N'étaient-ils pas enclins, sur ce thème, à rejoindre précisément les leçons des libéraux français qui avaient prôné la voie de l'esprit des siècles (prise en considération des données sociologiques, géographiques ou encore religieux du pays), au détriment de l'esprit de système, souvent résumé à la politique de la table rase, appliqué par la Révolution? Sur ce terrain, Silvestre Pinheiro Ferreira, exilé en France, constitue à n'en pas douter le représentant le plus original, lui qui désirait abroger l'article 71 de la Charte, prétextant qu'il appartenait à tous les pouvoirs, et plus encore à tout un chacun, de veiller et de conserver les institutions ${ }^{150}$. Ses principes du droit public et des gens, également parus en français, développeront d'ailleurs cette approche singulière du sujet qui mériterait sans doute une étude à part ${ }^{151}$; son ton critique contre l'institution royale invalide toutefois la thèse précitée de Selvino Antonio Malfatti pour qui le pouvoir modérateur brésilien serait largement inspiré de ses idées, sauf à le considérer comme partie intégrante des «publicistes modernes » qui étudièrent la question. En tout état de cause, ses écrits influenceront les parlementaires portugais, eux qui s'en inspiraient afin de contrer, à la suite de la parenthèse migueliste, toute résurgence absolutiste, supposée ou réelle. Pourfendant la prétendue dualité royale, en particulier les vertus attribuées à la partie «institutionnelle » du Roi, le député Barreto Feio $^{152}$ s'inspirait manifestement de Pinheiro Ferreira lorsqu'il recommandait à chaque citoyen de faire preuve de vigilance, compte tenu de la mission qui leur incombe :

«Le roi exerce le pouvoir exécutif, ce même roi exerce le pouvoir modérateur; en tant que Chef du pouvoir exécutif, la constitution reconnaît qu'il peut errer, ou qu'il peut ne pas tout voir ; en tant que pouvoir modérateur, la Commission veut nous faire croire qu'en vertu de l'élévation de sa position, il est devin et omniscient, au-dessus des passions et ne puisse jamais errer; ce qui non seulement est absurde, mais également déshonorant, car en voulant faire d'un homme un Dieu, les membres de la Commission se

\footnotetext{
${ }^{146}$ Intervention du député Silva Cabral, 6 mars 1845, in Ibid., legislatura 5, sessão 4, n 48, p. 8.

${ }^{147}$ Symbolisé par le célèbre Manifesto dirigido à nação portuguesa bem como aos soberanos e povos da Europa.

${ }^{148}$ On retrouve régulièrement ce type de convictions soulignant la singularité du modèle lusophone. Pour un exemple plus tardif, voir l'intervention du député Medeiros in Diario da Câmara dos Senhores Deputados da Nação Portugueza, legislatura 23, sessão 1, nº70, 13 avril 1880, p. 1398. La conviction est partagée par les conservateurs Brésiliens, y compris au XX $\mathrm{X}^{\mathrm{e}}$ siècle ; on la retrouve tout le long de l'ouvrage de J. de Scantimburgo.

${ }^{149}$ Les traces de ce débat se rencontrent encore dans les années 1870. Voir l'intervention de Francisco Mendes (Ibid., legislatura 20, sessão 1, n82, 29 août 1871, p. 434) et plus encore le débat du 25 janvier 1875.

${ }^{150}$ S. Pinheiro Ferreira, Observações sobre a ...carta constitucional do Reino de Portugal, op. cit., p. 155.

${ }^{151}$ Limitions-nous ici à cet extrait : «La partie du pouvoir conservateur qui concerne le maintien des droits civils et politique, est commune à tous les citoyens, et ils l'exercent en faisant usage du droit de pétition ou de la résistance légale. Quant au maintien de l'harmonie et de l'indépendance des pouvoirs politiques, les agents de chacun de ces quatre pouvoirs doivent être investis, par la constitution, d'un certain nombre d'attributions tendant à ce but commun ». S. Pinheiro Ferreira, Principes du droit public, constitutionnel, administratif, et des gens, Paris, Rey et Gravier, 1834, tome I, pp. 350-351.

${ }^{152}$ Libéral et admirateur de la constitution de Cadix, José Vitorino Barreto Feio (1782-1850) est surtout connu pour ses prises de position contre D. Miguel, qu'il condensa dans un pamphlet virulent. Il s'exila un temps en France.
} 
déchoient eux-mêmes de la condition d'homme libre. Tout citoyen a l'impérieux devoir de veiller sur la sûreté publique, et d'informer du danger ceux qui sont placés à la tête de l'Etat ${ }^{153}$.

Nombre d'interventions prolongent cette pensée. En 1885, le futur président de la République Bernardino Machado, tout en définissant «l'acte modérateur », attestait l'existence de plusieurs « pouvoirs modérateurs » :

«L'acte modérateur désigne tout acte par lequel un pouvoir ou branche du pouvoir intervient dans la sphère de compétence d'un autre pouvoir ou branche du pouvoir. En conséquence, quand le pouvoir royal, le seul que notre charte nomme modérateur, bien qu'il existe en fait d'autres pouvoirs modérateurs et en particulier celui des chambres, chargé de veiller sur notre constitution ; quand le pouvoir royal [dis-je] intervient dans le processus législatif, il assume un rôle modérateur $»^{154}$.

Si cette voie originale devait ainsi resurgir de temps à autre, elle n'en demeurait pas moins exceptionnelle. La plupart du temps, les parlementaires portugais exposent leurs doutes sur des points de droit souvent techniques qui trahissent des préoccupations proches de celles de leurs confrères brésiliens. L'important débat du 27 février 1835, repris avec moins d'entrain le 4 mars, illustre d'ailleurs l'envergure du problème qui animera plus tard le Brésil. L'objet de la dispute reposait sur le recours à l'adresse par la chambre, plus exactement de savoir s'il lui était permis de suggérer au pouvoir modérateur de prononcer la dissolution de cette même assemblée. Loin d'invoquer les publicistes français, dont l'absence doit être soulignée, les parlementaires, tel le marquis de Saldanha, s'appuyaient volontiers sur le «pouvoir modérateur anglais », en vérité sur les traditions environnant la prérogative royale, afin de soutenir une telle proposition :

« [...] personne n'oserait affirmer qu'en Angleterre, une adresse respectueuse au souverain, sur n'importe quel objet, sera considérée comme une attaque contre le Pouvoir Modérateur. [...] Il y a deux ans, le duc de Wellington fit voter dans la chambre des lords une pétition afin d'inciter le roi à modifier sa politique vis-àvis du Portugal ; ce Pouvoir Modérateur reçut la pétition et, sans se sentir offensé, y répondit [...]. Il y a peu le roi d'Angleterre, usant des prérogatives du Pouvoir Modérateur, a dissout le parlement [...]» ${ }^{155}$.

La référence au Portuguese Act de 1833 sert de prétexte à une lutte de partis cherchant à introduire ou à repousser le parlementarisme anglais. Jeu de dupes se perpétuant jusqu'à la fin de la monarchie, mais dont la victime sera inlassablement la même : le pouvoir royal. En effet, les partis politiques portugais, conservateurs (Partido Regenerador ${ }^{156}$ ) ou progressistes (Partido Historico ${ }^{157}$, Partido Reformista ${ }^{158}$ puis, après leur fusion en 1876, Partido Progressista ${ }^{159}$ ), ne se soucient de la prérogative royale qu'une fois rentrés dans l'opposition. Cette défense aléatoire et intéressée du pouvoir modérateur, invoqué afin d'incommoder le ministère au pouvoir en espérant sa chute, se cristallise souvent sur la question de la responsabilité des actes du pouvoir modérateur. La charte ne prévoyait rien à ce sujet : les ministres supportaient le faix de la responsabilité pour les actes du

\footnotetext{
153 Intervention du député Barreto Feio, in Diario da Câmara dos Senhores Deputados da Nação Portugueza, legislatura 1, sessão 2, n³3, 27 février 1835, p. 444.

${ }^{154}$ Bernardino Machado, Ibid., legislatura 25, sessão 2, nº74, 2 mai 1885, p. 1401.

155 Intervention du marquis de Saldanha, in Ibid., legislatura 1, sessão 2, n³3, 27 février 1835, p. 434. Saldanha vise ici la Portuguese motion de 1833, qui dissimulait, de façon plus ou moins voilée, une motion de censure. Sur ce cas, voir D. Baranger, Parlementarisme des origines, Paris, P.U.F., coll. Léviathan, 1999, p. 344 et s.

156 Tenants du «progressisme conservateur », ses membres (citons Saldanha, Aguiar ou encore Fontes, leur leader dans les années 1880 et le président du Conseil entre 1881 et 1886), désireux de poursuivre la politique des travaux publics afin de rattraper le retard économique du pays, sont partisans de l'ordre, et à ce titre du pouvoir en place.

${ }^{157}$ Formé de progressistes libéraux, de démocrates, des anciens setembristas et des derniers soutiens de Costa Cabral, ce parti entrera pour la première au pouvoir en 1856 avec le marquis de Loulé.

158 Né en 1867, en réaction au premier gouvernement «mixte» (alliance entre Partido Regenerador et Partido Historico), ce parti à la durée de vie éphémère défendait surtout un programme de réduction des dépenses publiques.

${ }^{159}$ Parmi ses principaux leaders, citons Anselmo José Braancamp et surtout José Luciano de Castro.
} 
pouvoir exécutif, pas pour ceux du pouvoir modérateur. Ce dernier étant déclaré inviolable ${ }^{160}$, la difficulté se présentait régulièrement aux députés au moins jusqu'aux années $1880^{161}$. Un exemple savoureux peut à ce titre être mentionné: en 1878, José Luciano de Castro, du Partido Progressista, interdisait aux ministres d'endosser la responsabilité des actes du pouvoir modérateur, afin de le préserver de tout empiétement du pouvoir exécutif mais aussi de toute influence néfaste, préservant ainsi son rôle d'arbitre au-dessus des partis ${ }^{162}$. En 1880, alors au pouvoir, celui-ci va défendre l'idée inverse, rencontrant de ce fait l'ironie du député Hintze Ribeiro, du Partido Regenerador et accessoirement futur président du Conseil, qui s'amuse alors à lui rappeler ses positions «d'antan ${ }^{163}$.

Cette anecdote ne parait pourtant pas si anodine. D’une part, elle démontre, en dépit des revirements, le souci d'adopter des mesures concrètes visant à clairement dissocier le pouvoir exécutif du pouvoir modérateur afin de donner une chance à ce dernier : en 1878, devançant Luciano de Castro, le vicomte de Moreira de Rey fustigeait les tentatives de rendre les ministres responsables des actes du pouvoir modérateur, propres à transformer la nature de ses attributions et à altérer l'équilibre institutionnel ${ }^{164}$. D'autre part, elle trahit malgré elle une conception double du pouvoir modérateur dans la pensée des parlementaires. La fonction de superintendance constitutionnelle, d'une part, héritière des pouvoirs régulateurs de la Révolution française : défendue par les seuls ministres et leurs soutiens, cette mission semble pourtant servir de prélude à l'effacement du roi, parfois au nom de la théorie du pouvoir neutre de Constant ${ }^{165}$. La tradition de l'arbitre au-dessus des partis, d'autre part, pérennisée par les concepteurs du pouvoir conservateur : appréhendée par les partis classiques une fois entrés dans l'opposition, cette mission pourrait n'être qu'un expédient ingénieux destiné à handicaper la marche du gouvernement ou à détourner l'opinion publique des sirènes républicaines ${ }^{166}$.

Nous avons déjà souligné l'absence énigmatique d'Henri Fonfrède dans les débats, lui dont la présence s'affiche ostensiblement au Brésil dans les milieux conservateurs; ses idées ne sont pas pour autant totalement absentes. Elles nous semblent apparaître sous le règne éphémère de la constitution de 1838, privée de tout pouvoir modérateur: le 21 février 1839, le député Oliveira Marreca répond à une invective d'un élu se présentant comme le représentant de l'élément démocratique du pays. Son intervention reprend expressément la dénomination de pouvoir modérateur, pour en modifier radicalement le sens : ce pouvoir n'est en effet pas exercé par une

\footnotetext{
${ }^{160}$ Même s'il est parfois fait mention d'une responsabilité morale pesant sur lui. Pour un exemple : J. Luciano de Castro, in Diario da Câmara dos Senhores Deputados da Nação Portugueza, legislatura 24, sessão 2, n ${ }^{\circ}$, 23 janvier 1883 , p. 111.

${ }^{161}$ Il est ainsi exagéré d'affirmer, comme J. Miranda, Manual de direito constitucional, op. cit., t. I, p. 280 en note, que les ministres ont toujours été réputés responsables des actes du pouvoir modérateur. La question se repose inlassablement et ce n'est visiblement qu'en 1883 que Fontes, alors président du Conseil, se permet d'affirmer que cette responsabilité relève du «droit coutumier » portugais (il vaudrait mieux parler de convention de la constitution). Cf. Diario da Câmara dos Senhores Deputados da Nação Portugueza, legislatura 24, sessão 2, n¹9, 30 janvier 1883 , p. 208. L'article 7 de l'acte additionnel du 24 juillet 1885 entérinera en grande partie cette solution, non sans avoir au préalable suscité un intense débat tout au long du printemps.

${ }^{162}$ Luciano de Castro, Ibid., legislatura 21, sessão 4, n 66,16 octobre 1878, p. 1129 et s. Son approche du pouvoir modérateur, arbitre au-dessus des partis, est bien mieux développée dans son intervention du 25 avril 1879 (Ibid., legislatura 22, sessão $1, \mathrm{n}^{\circ} 79$, p. 1367) où il s'efforce d'écarter le spectre du chef d'Etat républicain.

${ }^{163}$ Hintze Ribeiro, Ibid., legislatura 23, sessão 2, n 19,29 janvier 1880 , p. 303.

${ }^{164}$ Vicomte de Moreira de Rey, Ibid., legislatura 21, sessão 4, nº5, 15 avril 1878, p. 1231.

${ }^{165}$ L'intervention du député Aoila du 6 mars 1852 le démontre : réduisant la théorie du pouvoir neutre de Constant à la célèbre maxime de Thiers, il en déduit que le roi ne peut mal faire, sous-entendant qu'il ne doit rien faire. Voir Ibid., legislatura 8, sessão $2, n^{\circ} 50$, p. 93.

${ }^{166}$ Elle engendre malgré tout certaines interrogations pertinentes. Le professeur de droit José Dias Ferreira, député indépendant qui deviendra président du Conseil dans les années 1890, souhaitait ainsi exclure les membres de la famille royale de tout parti politique et de toute assemblée, afin d'empêcher les interférences visant à détourner le roi de sa fonction impartiale d'arbitre. Voir Ibid., legislatura 21, sessão 4, nº5, 15 avril 1878, p. 1122.
} 
institution ou un organe, mais par la partie modérée de la représentation nationale, le « centre moral et constitutionnel » selon ses propres dires. La mission de ce juste milieu vise à contenir les «éléments sociaux » radicaux, absolutistes comme démocratiques, également représentés au sein de la chambre, afin de préserver le pays de la lutte de partis ${ }^{167}$. Il s'agit, en d'autres termes, de faire intervenir un arbitre entre les partis qui ne soit pas une aristocratie, accusation ici repoussée.

Le contexte explique aisément l'apparition de ce type de considérations. Si les députés rechignent souvent à l'admettre, le pouvoir modérateur du roi devait à son tour s'imprégner d'une telle approche du sujet, encline à s'écarter de pures considérations constitutionnelles pour embrasser l'aspect social et politique de la question. Des suppliques, visant au recueillement de la nation meurtrie par la guerre civile et désireuse de paix sociale, se rencontrent en effet à l'occasion des nombreux débats sur le droit d'amnistie. En 1848, le député Vaz Preto ${ }^{168}$ sublimait, parmi les prérogatives du pouvoir modérateur, sa faculté de commander l'oubli et sa capacité à transformer les dissensions en simples querelles constitutionnelles :

« Du haut de son Trône chutèrent ces paroles, M. le président : oubli du passé. Ces paroles, descendues du Trône, semblent provenir du Ciel. Oubli du passé, telles ont été les paroles proférées par l'Auguste Chef de l'Etat dans l'exercice des sublimes attributions du pouvoir modérateur, que lui confère la Loi fondamentale ; paroles en même temps maternelles d'une Souveraine qui aime ses sujets comme ses propres fils. [...] Nous avons tous erré ; nous devons tous oublier ; nous avons tous besoin de voir nos erreurs oubliées. [...] Il est nécessaire que nous, Portugais placés autour du Trône Constitutionnel de Notre Reine, renoncions une fois pour toute aux expédients anarchiques, séditieux et révolutionnaires, et que nos luttes deviennent enfin ceux de la raison, de l'intelligence, du raisonnement, livrées seulement au sein de la presse et du parlement ${ }^{169}$.

Dans ces circonstances, l'exercice du pouvoir modérateur par les derniers rois du Portugal mérite un instant d'attention. Le règne mouvementé de D. Maria II jusqu'en 1853 n'est peut-être pas le plus intéressant ${ }^{170}$; mais, par sa conduite et surtout par le soutien offert à deux reprises à un parti lors de l'épisode connu sous le nom de Belenzada (nuit du 4 au 5 novembre 1836) et plus encore lors de l'Emboscada (6 octobre 1846), en faveur de Costa Cabral, celle-ci démontrait ne pas se contenter d'un rôle constitutionnel. Sa célèbre proclamation de 1846 justifiait ce choix partisan au nom de l'état de nécessité ${ }^{171}$ : la sauvegarde de la Charte exigerait de sa part une conduite active, l'approchant des pouvoirs conservateurs qui se réservaient le plus souvent l'exercice des pleins pouvoirs en période de grave crise politique ${ }^{172}$. Symbolisée par la figure docile de D. Fernando, époux de D. Maria II, la ligne politique royale s'inscrira manifestement toujours dans cette voie de la préservation de la paix sociale, à n'importe quel coût ${ }^{173}$. Elle offre pourtant deux visages radicalement opposés. D'une part, celui du règne de $\mathrm{D}$. Luis (1861-1889) est marqué par la volonté de ne pas intervenir dans la politique, acceptant pleinement sa fonction de monarque constitutionnel

\footnotetext{
167 Oliveira Marreca, Ibid., legislatura 3, sessão 2, n40, 21 février 1839, p. 351.

168 L'archevêque Marcos Pinto Soares Vaz Preto (1782-1851) était libéral et franc-maçon. Il fut notamment le confesseur de D. Pedro IV et de sa fille D. Maria II.

${ }^{169}$ Vaz Preto, in Diario da Câmara dos Senhores Deputados da Nação Portugueza, legislatura 7, sessão 1, nº, 9 mars 1848, p. 13.

${ }^{170}$ Les plus cyniques estimaient d'ailleurs que ses « occupations » l'empêchaient de régner véritablement : la reine est effectivement morte en 1853 à l'âge de 34 ans lors de l'accouchement de son onzième enfant...

${ }^{171}$ L'argument ne convainquit guère ses opposants et lui valut de nombreux pamphlets dont le plus célèbre s'intitule Estado da Questão. Pour son auteur, D. Maria II, en quittant sa sphère d'inviolabilité, doit désormais être considérée non comme une reine constitutionnelle, mais comme une factieuse.

${ }^{172}$ Cette attitude engendrera, comme au Brésil (Chr. Lynch, O Momento Monarquiano, op. cit., pp. 307-309), une lutte âpre et récurrente relative à l'interprétation de l'expression « sauvegarde de l'Etat » : glosant la Charte, les détracteurs du pouvoir modérateur estimaient qu'il ne peut dissoudre l'assemblée qu'en cas de crise grave avérée. Les conservateurs jugeaient au contraire qu'une simple atteinte à l'équilibre des pouvoirs peut légitimer la dissolution.

${ }^{173}$ Sur ce point et sur l'attitude des rois portugais, voir J. Hermano Saraiva, Historia de Portugal, Sintra, Publicações

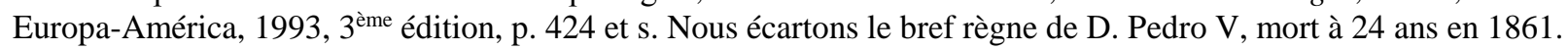


placé en retrait ${ }^{174}$. D'autre part, le règne de D. Carlos (1889-1908) se voulait autrement plus incisif, adoptant une approche du pouvoir modérateur qui nous paraît semblable à celle des pouvoirs conservateurs. Si le premier s'inscrit dans la logique programmatique de Thiers, en dépit de bien des critiques n'y voyant qu'un mythe inadaptable au cas portugais ${ }^{175}$, le second, en se voulant plus actif, est pourtant souvent décrit comme un tenant du césarisme ; son mode de gouvernement serait autant puisé chez Bismarck que chez Napoléon III. La montée du républicanisme et la dégradation morale des esprits justifiaient selon les monarchistes l'accaparement du pouvoir par un homme providentiel chargé de redresser le pays ; en vérité, les républicains eux-mêmes accréditaient cette thèse du déclin portugais, admettant l'idée d'un Président de la République investi du pouvoir dictatorial provisoire ${ }^{176}$. L'air du temps était manifestement favorable aux entreprises personnelles. Bien qu'il dut parfois céder, notamment en 1893, Dom Carlos cherche ainsi à gouverner et à imposer ses idées à travers des ministères composés d'indépendants, en particulier le fidèle João Franco $^{177}$, faisant fi du résultat des élections et de l'alternance politique consacrée par son prédécesseur. La confiscation du pouvoir réglementaire, introduit par l'article 6 du décret dictatorial du 25 septembre 1895, visait à consolider encore un peu plus sa position dominante. Comme le déplorera Dias Ferreira dans l'hémicycle, cette attitude finissait par corrompre la nature du pouvoir modérateur, lui qui le comprenait à la lumière de Benjamin Constant ${ }^{178}$. L'assassinat de D. Carlos en 1908 marquera toutefois la fin de cette tentative ; la monarchie ébranlée devait à son tour disparaitre en 1910, emportant avec elle l'institution du pouvoir modérateur.

\section{Conclusion :}

«Le pouvoir modérateur doit se cantonner au maintien du juste équilibre entre les différents pouvoirs de l'Etat. Afin d'assurer le respect des libertés constitutionnelles, nous avons besoin, en premier lieu et avant toute chose, de confier au peuple le droit de gouverner en proportion de l'avancement de la civilisation, l'accompagnant ainsi dans son cheminement vers l'émancipation. Par ailleurs, je ne puis adhérer à la doctrine de M. le président du conseil [Luciano de Castro], qui souhaite ériger le pouvoir modérateur au rang de juge arbitre des partis. Personne n'a le pouvoir d'être un arbitre entre les partis, en dehors des collèges électoraux ou du peuple lui-même. Les partis légalement formés se nourrissent de la vie du pays. Le pouvoir modérateur, lorsqu'il nomme le gouvernement, n'a pas à effectuer un arbitrage entre les partis. Il doit étudier les nécessités publiques et les tendances de la nation. Le parti qui, à un moment donné, bénéficie du soutien du pays, doit être appelé à gouverner par le roi ; celui-ci n'agit alors pas comme arbitre, mais comme l'écho de la volonté populaire ${ }^{179}$. Par cette brillante invective, le professeur de droit José Dias Ferreira offrait ostensiblement un choix aux Portugais, tirant parti de l'étendue des sources et des conceptions du pouvoir modérateur. En France, au Portugal et au Brésil, ce quatrième pouvoir s'envisageait en effet de deux façons différentes. Il est possible, en premier lieu, de l'appréhender tel un pouvoir régulateur, chargé simplement de veiller au respect de la constitution, comprise alors comme un mécanisme ; le pouvoir modérateur s'efface ainsi des luttes partisanes, mais n'a pas à les

\footnotetext{
${ }^{174}$ Les républicains en profitaient pour souligner l'inutilité du quatrième pouvoir. Voir José Elias Garcia in Diario da Câmara dos Senhores Deputados da Nação Portugueza, legislatura 24, sessão 3, n²3, 5 février 1884, p. 225.

${ }^{175} \mathrm{La}$ critique provient des républicains comme Manuel de Arriaga : voir Ibid., legislatura 24, sessão 3, n 79,16 mai 1884, pp. 1626-1627. Celui-ci devait également contrer les tenants du pouvoir conservateur du roi : pour lui, le chef de l'Etat, en retenant ne serait-ce que le droit de nomination des ministres, constitue «l'origine des principales perturbations sociales ».

${ }^{176}$ Face à ces deux extrêmes, Eduardo Abreu exprima son profond désaccord, ne comprenant pas où se situait le risque d'anarchie tant agité. Voir Ibid., legislatura 28, sessão 2, n8, 14 mars 1891, p. 14.

${ }^{177}$ Bien qu'issu du Partido Regenerador, Franco était totalement dévoué au roi. Le programme politique mis en œuvre, surnommé «franquismo », provient en vérité du roi lui-même.

${ }^{178}$ Voir l'intervention de Dias Ferreira in Diario da Câmara dos Senhores Deputados da Nação Portugueza, legislatura 31 , sessão $1, \mathrm{n}^{\circ} 155,26$ janvier 1896, p. 6.

${ }^{179}$ Dias Ferreira, Ibid., legislatura 32, sessão 3, n 115,17 juillet 1899, p. 27.
} 
arbitrer : il écoute le vœu de l'opinion publique et requiert, si le besoin se fait sentir, le jugement de l'électorat pour décider du sort de la majorité parlementaire. En second lieu, ce quatrième pouvoir peut tout autant être dépeint sous les traits d'un pouvoir conservateur, arbitrant des conflits entre les partis politiques, eux-mêmes représentants des divers intérêts présents au sein du pays ; autorité tutélaire pesante, représentant seul l'intérêt général, qui peut, le cas échéant et de façon vertueuse, se saisir du pouvoir dictatorial afin de redresser l'Etat.

Le sort du quatrième pouvoir, dans les seuls pays ayant consacré l'idée dans leurs constitutions, n'est finalement pas surprenant ; le destin s'amuse à opposer et à confondre deux conceptions antinomiques unies par une dénomination commune trompeuse. Ainsi se perpétue la croyance en la paternité de Benjamin Constant, sans mesurer l'écart qui existe entre ses doctrines, les constitutions lusophones et la pratique du pouvoir au Portugal et au Brésil. S'il éclipse ses contemporains par son talent, le libéral de Coppet n'est jamais parvenu à faire triompher son pouvoir neutre. La querelle des influences perdurera tant que nous ne reconnaîtrons pas que le pouvoir modérateur brésilien et portugais s'inspire, dès l'origine, d'une multitude de publicistes libéraux, la plupart français. L'ombre de Lanjuinais semble s'imposer en 1824 et 1826 ; l'implication tardive du pouvoir modérateur dans les affaires, due aux difficultés conjoncturelles, empêchera pourtant le triomphe de sa doctrine, tombée dans l'oubli. La pratique politique dans ces deux pays, née pour l'essentiel dans les années 1840-1860, occulte en effet les libéraux français de la Restauration, sauf à invoquer Constant, sans le comprendre et parfois sans le lire. Les conservateurs comme les progressistes puisent leurs idées ailleurs: les uns dans les doctrines contre-révolutionnaires (Bonald et Donoso Cortes pour le XIX ${ }^{\mathrm{e}}$ siècle, Maurras et Maritain pour le $\mathrm{XX}^{\mathrm{e}}$ siècle ${ }^{180}$ ) ou dans le libéral conservateur de référence sur le sujet, Henri Fonfrède ; les autres, dans les auteurs ou plutôt la pratique anglaise telle qu'ils se la représentent. Il en résulte deux défenses singulières du pouvoir modérateur, ne s'inspirant ni de Constant, ni de Lanjuinais : l'une abrite le pouvoir conservateur dans sa version la plus réactionnaire afin de procéder à une épuration morale de l'Etat et de la société ; l'autre adapte les maximes anglaises, afin de minimiser le rôle et l'influence du roi ou de l'Empereur et ainsi offrir le champ libre à la représentation nationale. La montée du républicanisme et le risque révolutionnaire entretiendront pourtant la confusion de ces deux approches, unies face à l'adversité ${ }^{181}$. Après tout, la critique de Dias Ferreira visait nommément Luciano de Castro, symbole de l'union sacrée des défenseurs de la monarchie constitutionnelle : le chef des libéraux progressistes était en effet entré en politique en qualité de député du Partido Regenerador, sans jamais renier ses convictions relatives au pouvoir royal.

La victoire des républicains ne laisse subsister qu'une interrogation : «inventer un quatrième pouvoir », est-ce vraiment «vouloir une chose qui ne se justifie pas » suivant l'affirmation de José Elias Garcia ${ }^{182}$ ? La persistance de l'idée, régulièrement désirée au Brésil par les républicains de la première génération (Alberto Torres ${ }^{183}$, Borges de Medeiros ${ }^{184}$ ) et par des conservateurs acquis,

\footnotetext{
${ }^{180}$ J. de Scantimburgo les utilise tout le long de son ouvrage consacré au pouvoir modérateur.

${ }^{181}$ L'attitude rappelle celle des tenants de la monarchie constitutionnelle en France après la chute de Louis-Philippe. Victor Cousin en est une figure remarquable : le rôle du roi est minime dans son esprit, proche des thèses de Thiers et de la figure du roi anglais. Mais, dans un article de 1851, Cousin va présenter une subtilité digne d'intérêt : le roi y est décrit comme la clef de voûte de l'édifice (V. Cousin, Des principes de la Révolution française et du gouvernement représentatif, suivi de discours politiques, Paris, Didier, 1864, p. LXXIII, reprise d'un article du $1^{\mathrm{er}}$ avril 1851 paru dans la Revue des Deux Mondes). Sa présence permet aux «partis honnêtes » de livrer une bataille idéologique sans retenue; or, ces partis sont précisément chargé de représenter, l'un, les intérêts conservateurs, l'autre, les intérêts innovateurs. Le roi veille en assurant l'alternance, mais Cousin esquisse en filigrane une idée plus intrigante en s'inspirant, comme les Brésiliens, des whigs et des tories: les deux partis sont destinés à être en quelque sorte institutionnalisés par le roi, pour le bien-être des institutions. Le mot clé devait être lâché un peu plus loin : la reine Victoria se contente d'exercer un « rôle modérateur que la constitution lui assigne » (Ibid., p. LXXV)...

182 José Elias Garcia in Diario da Câmara dos Senhores Deputados da Nação Portugueza, legislatura 24, sessão 3, n²3, 5 février 1884 , p. 225.

${ }^{183}$ Et sa théorie du «pouvoir coordinateur » (poder coordenador) contenue dans son livre A Organização social, Rio de Janeiro, Imprensa Nacional, 1914.
} 
faute de mieux, à la démocratie (João de Scantimburgo), ou encore la propension à décrire le pouvoir du Président de la République portugaise tel un pouvoir modérateur ${ }^{185}$ permettent d'en douter. Nous ne sommes toutefois pas surpris de rencontrer à nouveau la confusion entre les deux approches du pouvoir modérateur, fluctuant là encore au gré des conjonctures difficiles envenimées par des luttes d'intérêts. Mais n'est-ce pas là, en dernière analyse, le véritable quatrième pouvoir que l'on souhaite inventer afin de vouloir une chose qui se justifie dans toute société ? Un pouvoir, autrement dit, qui ne devient légitime et indispensable que parce qu'il permet de mettre en œuvre les principes politiques modernes (garanties contre l'Etat, constitution, souveraineté nationale, représentation, débats, émancipation de l'individu...) en ôtant tout risque de rejet ou d'extrémisme.

\section{Résumé :}

Une tradition bien établie attribue au seul Benjamin Constant la paternité du poder moderador consacré par la Constitution brésilienne de 1824 et la Charte portugaise de 1826. Octroyées par un même souverain, Dom Pedro, celles-ci adapteraient sa théorie du pouvoir neutre. Une telle affirmation n'est pourtant pas si évidente et ne résiste ni à l'étude de la pratique politique des contrées lusophones, ni à une analyse même superficielle des textes. Le pouvoir modérateur ne s'inspirerait-il pas d'une multitude d'auteurs qui, comme Lanjuinais ou Fonfrède, proposèrent une vision concurrente du pouvoir royal ?

Mots clés : Benjamin Constant; Brésil impérial; Jean-Denis Lanjuinais; Portugal ; pouvoir conservateur ; pouvoir coordinateur ; pouvoir modérateur ; pouvoir neutre ; pouvoir préservateur ; pouvoir royal ; quatrième pouvoir.

\footnotetext{
${ }^{184}$ Borges de Medeiros, O poder moderador na Republica Presidencial, Recife, s. e., 1933. Lui-même reconnaissait dans cet ouvrage la paternité conjointe de Lanjuinais et de Constant.

${ }^{185}$ Comme le fait Roxane Garnier, Un modèle européen de démocratie : le cas portugais, op. cit., pp. 325-395.
} 